\title{
Cognitive reframing for carers of people with dementia (Review)
}

\author{
Vernooij-Dassen M, Draskovic I, McCleery J, Downs M
}

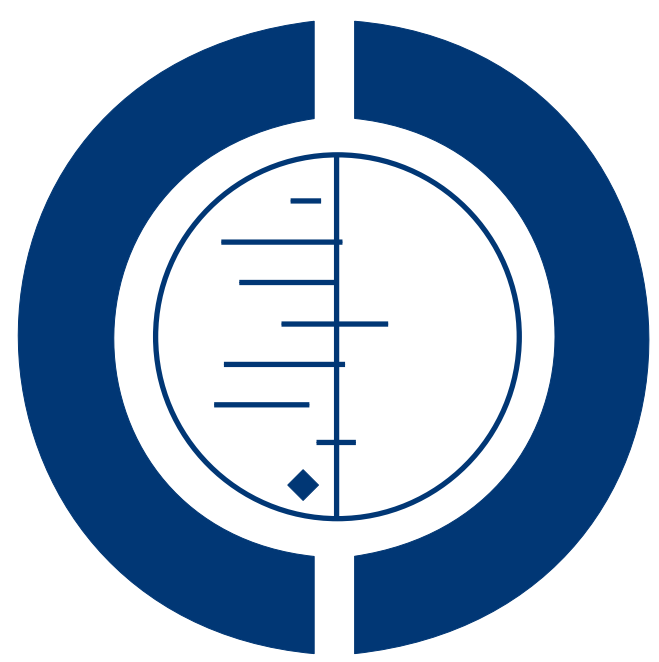

\section{THE COCHRANE COLLABORATION $^{\circledR}$}

This is a reprint of a Cochrane review, prepared and maintained by The Cochrane Collaboration and published in The Cochrane Library 2011, Issue 11

http://www.thecochranelibrary.com

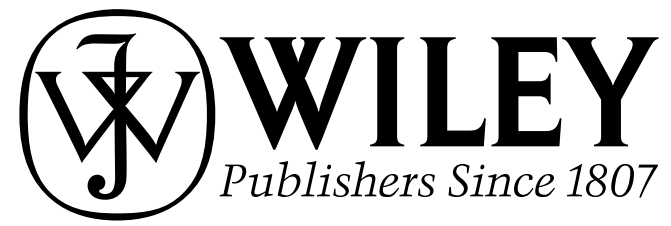

Cognitive reframing for carers of people with dementia (Review)

Copyright $\odot$ 20II The Cochrane Collaboration. Published by John Wiley \& Sons, Ltd. 
TABLE OF CONTENTS

HEADER . . . . . . . . . . . . . . . . . . . . . . . . . . . . . . . . . . . . . . . 1

ABSTRACT . . . . . . . . . . . . . . . . . . . . . . . . . . . . . . . . . . . . . . . . . . . . 1

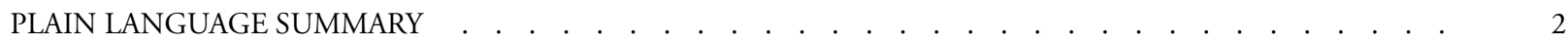

BACKGROUND . . . . . . . . . . . . . . . . . . . . . . . . . . . . . . . . . . . . . 2

OBJECTIVES . . . . . . . . . . . . . . . . . . . . . . . . . . . . . . . . . . . . . . . . . . . . . .

METHODS . . . . . . . . . . . . . . . . . . . . . . . . . . . . . . . . . . . . . . 3

RESULTS . . . . . . . . . . . . . . . . . . . . . . . . . . . . . . . . . . . . . . . 5

Figure 1. . . . . . . . . . . . . . . . . . . . . . . . . . . . . . . . . . . . . . 8

Figure 2. . . . . . . . . . . . . . . . . . . . . . . . . . . . . . . . . . . . . . 8

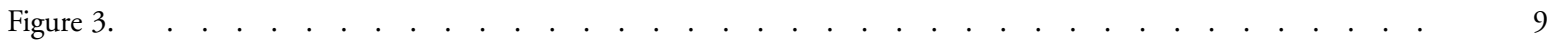

Figure $4 . \quad$. . . . . . . . . . . . . . . . . . . . . . . . . . . . . . . . . . . . . 9

Figure 5. . . . . . . . . . . . . . . . . . . . . . . . . . . . . . . . . . . . . . 10

Figure 6. . . . . . . . . . . . . . . . . . . . . . . . . . . . . . . . . . . . . . 10

DISCUSSION . . . . . . . . . . . . . . . . . . . . . . . . . . . . . . . . . . . . . . . $\quad . \quad 10$

AUTHORS' CONCLUSIONS . . . . . . . . . . . . . . . . . . . . . . . . . . . . . . . . . . . . . 11

ACKNOWLEDGEMENTS . . . . . . . . . . . . . . . . . . . . . . . . . . . . . . . . . . . . . . 11

REFERENCES . . . . . . . . . . . . . . . . . . . . . . . . . . . . . . . . . . . . . 12

CHARACTERISTICS OF STUDIES . . . . . . . . . . . . . . . . . . . . . . . . . . . . . . . . . . . $\quad$.

DATA AND ANALYSES . . . . . . . . . . . . . . . . . . . . . . . . . . . . . . . . . . . . . . . . . . . . . . . . $\quad . \quad 27$

Analysis 1.1. Comparison 1 Outcomes of cognitive reframing interventions, Outcome 1 Anxiety. . . . . . . . . $\quad 27$

Analysis 1.2. Comparison 1 Outcomes of cognitive reframing interventions, Outcome 2 Depression. . . . . . . . 28

Analysis 1.3. Comparison 1 Outcomes of cognitive reframing interventions, Outcome 3 Burden. . . . . . . . . $\quad$. 28

Analysis 1.4. Comparison 1 Outcomes of cognitive reframing interventions, Outcome 4 Coping/self efficacy. . . . $\quad 29$

Analysis 1.5. Comparison 1 Outcomes of cognitive reframing interventions, Outcome 5 stress/distress. . . . . . . 30

Analysis 1.6. Comparison 1 Outcomes of cognitive reframing interventions, Outcome 6 RMBPC-reaction. . . . . 30

ADDITIONAL TABLES . . . . . . . . . . . . . . . . . . . . . . . . . . . . . . . . . . 30

APPENDICES . . . . . . . . . . . . . . . . . . . . . . . . . . . . . . . . . . . . . 31

HISTORY . . . . . . . . . . . . . . . . . . . . . . . . . . . . . . . . . . . . . . . 36

CONTRIBUTIONS OF AUTHORS . . . . . . . . . . . . . . . . . . . . . . . . . . . . . . . . . . . . . . . 36

DECLARATIONS OF INTEREST . . . . . . . . . . . . . . . . . . . . . . . . . . . . . . . . . . . . .

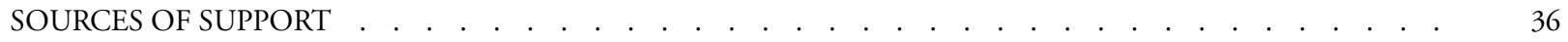

DIFFERENCES BETWEEN PROTOCOL AND REVIEW . . . . . . . . . . . . . . . . . . . . . . . . . 36

Cognitive reframing for carers of people with dementia (Review)

Copyright ( 201 I The Cochrane Collaboration. Published by John Wiley \& Sons, Ltd. 


\title{
[Intervention Review]
}

\section{Cognitive reframing for carers of people with dementia}

\author{
Myrra Vernooij-Dassen ${ }^{1}$, Irena Draskovic ${ }^{2}$, Jenny McCleery ${ }^{3}$, Murna Downs ${ }^{4}$ \\ ${ }^{1}$ Centre for Quality of Care Research/Alzheimer Center, Radboud University Nijmegen Medical Center, Nijmegen, Netherlands. \\ ${ }^{2}$ Primary and Community Care, RUNMC, Nijmegen, Netherlands. ${ }^{3}$ Cochrane Dementia and Cognitive Improvement Group, Uni- \\ versity of Oxford, Oxford, UK. ${ }^{4}$ Bradford Dementia Group, Division of Dementia Studies, School of Health Studies, Bradford, UK \\ Contact address: Myrra Vernooij-Dassen, Centre for Quality of Care Research/Alzheimer Center, Radboud University Nijmegen \\ Medical Center, PO Box 9101, Nijmegen, 6500 HB, Netherlands. M.Vernooij-Dassen@iq.umcn.nl.
}

Editorial group: Cochrane Dementia and Cognitive Improvement Group.

Publication status and date: New, published in Issue 11, 2011.

Review content assessed as up-to-date: 1 June 2011.

Citation: Vernooij-Dassen M, Draskovic I, McCleery J, Downs M. Cognitive reframing for carers of people with dementia. Cochrane Database of Systematic Reviews 2011, Issue 11. Art. No.: CD005318. DOI: 10.1002/14651858.CD005318.pub2.

Copyright (C) 2011 The Cochrane Collaboration. Published by John Wiley \& Sons, Ltd.

\begin{abstract}
A B S T R A C T
Background

The balance of evidence about whether psychosocial interventions for caregivers of people with dementia could reduce carers' psychological morbidity and delay their relatives' institutionalisation is now widely regarded as moderately positive (Brodaty 2003; Spijker 2008). Multi-component, tailor-made psychosocial interventions are considered to be particularly promising (Brodaty 2003; Spijker 2008). These interventions involve multiple mechanisms of action. In this review we focused solely on the effectiveness of one element within psychosocial interventions, cognitive reframing. Cognitive reframing is a component of cognitive behavioral therapy (CBT). In dementia care, cognitive reframing interventions focus on family carers' maladaptive, self-defeating or distressing cognitions about their relatives' behaviors and about their own performance in the caring role.
\end{abstract}

Objectives

The objective of this review was to evaluate the effectiveness of cognitive reframing interventions for family carers of people with dementia on their psychological morbidity and stress.

Search strategy

The trials were identified by searching (5 April 2009) the Cochrane Dementia and Cognitive Improvement Group Specialized Register, which contains records from major healthcare databases: The Cochrane Library, MEDLINE, EMBASE, PsycINFO, CINAHL and LILACS, ongoing trial databases and grey literature sources. For more detailed information on what the Group's specialized register contains and to view the search strategies see the Cochrane Dementia and Cognitive Improvement Group methods used in reviews.

The Cochrane Library, MEDLINE, EMBASE, PsycINFO, CINAHL, LILACS and a number of trial registers and grey literature sources were also searched separately on 5 April 2009.

Selection criteria

Randomised controlled trials of cognitive reframing interventions for family carers of people with dementia.

\section{Data collection and analysis}

Three assessors (MVD, ID, JmC) independently judged whether the intervention being studied was documented in a trial; two assessors assessed trial quality. 


\section{Main results}

Pooled data indicated a beneficial effect of cognitive reframing interventions on carers' psychological morbidity, specifically anxiety (standardised mean difference (SMD) $-0.21 ; 95 \%$ confidence interval (CI) -0.39 to -0.04 ), depression (SMD -0.66; $95 \%$ CI - 1.27 to -0.05 ), and subjective stress (SMD -0.23 ; $95 \%$ CI -0.43 to -0.04 ). No effects were found for carers' coping, appraisal of the burden, reactions to their relatives' behaviors, or institutionalization of the person with dementia.

\section{Authors' conclusions}

Cognitive reframing for family carers of people with dementia seems to reduce psychological morbidity and subjective stress but without altering appraisals of coping or burden. The results suggest that it may be an effective component of individualised, multi-component interventions for carers. Identifying studies with relevant interventions was a challenge for this review. The impact of cognitive reframing might be higher when used alongside other interventions because this offers better opportunities to tailor cognitive reframing to actual everyday carer problems.

\section{PLAIN LANGUAGE SUMMARY}

\section{Cognitive reframing for carers of people with dementia}

There is some evidence that cognitive reframing interventions for family carers of people with dementia are effective.

Dementia care is challenging for family carers. We studied whether they could be helped by cognitive reframing interventions. Cognitive reframing is intended to reduce carers' stress by changing certain of their beliefs, such as beliefs about their responsibilities to the person with dementia, their own need for support, and why their relatives behave as they do. We found that cognitive reframing has the potential to reduce anxiety, depression and stress. It did not affect carers' coping or sense of being burdened. This review concludes that cognitive reframing might be useful to improve the mental health of informal carers of people with dementia.

\section{B A C K G R O U N D}

Dementia is primarily a disease of older people, particularly those over 80 years. The number of people with dementia in Europe is currently 7.7 million and will double by the year 2050 (EuroCoDe 2009). Dementia is now recognized as a major public health issue. According to the World Health Organization (WHO), Alzheimer's disease and other dementias are rated as the fourth leading cause of burden of disease in high-income countries (WHO 2008). Dementia has a significant economic impact on health and social care services (Wimo 2007). The costs to social and healthcare organizations and the impact on families are expected to escalate in the coming decades. Preventing or minimizing the effects of family carer burden and stress are key government priorities. Family carers of people with dementia experience more burden than family carers of other people with chronic illness (Draper 1992), and they are at greater risk of developing depression (Joling 2010). Carer burden is associated with patients' behavioral problems (Machnicki 2008; van den Wijngaart 2007; Vernooij-Dassen 1997) and is a strong predictor of institutionalization (Gaugler 2008; Vernooij-Dassen 1997).
The balance of evidence about whether psychosocial interventions for caregivers of people with dementia could reduce carers' psychological morbidity and delay their relatives' institutionalization is now widely regarded as moderately positive (Brodaty 2003; Spijker 2008). Psychosocial interventions for family carers are more successful when they are tailor-made, include the person with dementia as well as the caregiver, offer a choice of interventions and are intensive (Brodaty 2003; Spijker 2008). However, these kinds of interventions involve multiple mechanisms of action. It is timely to try to identify the key ingredients responsible for the efficacy.

A key problem in dementia care is understanding and responding to the patient's behavior. Family carers often struggle to understand the cognitive decline and changing behavior of their loved one, often ascribing a negative meaning to their relative's behavior and blaming the person rather than the disease. Today we know that a person's behavior is often the result of an unmet (physical or psychosocial) need or a function of their interaction with a challenging physical or psychosocial environment. Not understating why their relative with dementia is behaving differently often leads family carers to experience distressing emotional states such 
as anger, anxiety, guilt and depression. While people can change the meanings or attributions they ascribe to situations, this often does not happen spontaneously. The positive effects of cognitive therapy, including cognitive restructuring, on a variety of stressrelated disorders (Gale 2000; Tolin 2010) suggest that it has potential for addressing the similar psychological morbidity of family carers of people with dementia. When used in psychosocial interventions for family carers, cognitive reframing focuses on changing self-defeating or distressing cognitions into those cognitions that support adaptive behaviour and reduce anxiety, depression and stress.

The theoretical framework of 'symbolic interactionism' is helpful in explaining how cognitive reframing might work. It states that the meaning people ascribe to a situation, in this case caring, is crucial to understanding how they will react. People tend to act upon the meaning they attribute to that situation. One of the assumptions of this theoretical perspective is that people are able to reflect on these attributions and to change them (Blumer 1969). This theoretical framework offers a perspective which when viewed alongside the work of Lazarus (Lazarus 1984) and Bandura (Bandura 1977) enables us to describe the mechanism whereby psychological morbidity develops in carers and, consequently, to identify ways to alleviate it.

Cognitive reframing focuses on altering maladaptive, self-defeating or distressing cognitions and makes them more adapted to the situation. This, in turn, is assumed to improve coping, reduce burden and psychological morbidity, improve quality of life and reduce healthcare costs. Thus cognitive reframing is hypothesized to:

- improve family carers' coping and self-efficacy, reduce family carers' burden, change family carers' appraisal of their relatives' behaviors;

- reduce family carers' psychological morbidity (including depression and anxiety) and stress;

- increase family carers' quality of life;

- reduce healthcare costs, particularly by preventing or delaying institutionalization.

The review aimed to clarify the effectiveness of cognitive reframing and thus provide a clear evidence base for clinical practice.

\section{O B JE C T IVES}

- To evaluate the effectiveness of cognitive reframing interventions with carers of people with dementia

- To indicate the nature and quality of the evidence available
- To contribute to providing an evidence base for clinical practice

\section{MET HO D S}

\section{Criteria for considering studies for this review}

\section{Types of studies}

Randomised controlled trials. No restrictions were applied as to length of the trial and number of measurements and assessments.

\section{Types of participants}

The participants were family carers taking care of a person with any type of dementia. The relationship of the family carer to the person with dementia was spouse, child, other family member or friend. Only interventions involving family carers of communitydwelling people with dementia have been considered for inclusion.

\section{Types of interventions}

An intervention was accepted as 'cognitive reframing' if the authors specified the main goal of the intervention as being the reduction of caregiver problems, as named above, by means of the identification and modification of some or all of the following:

- family carers' beliefs about their own responsibilities to the people with dementia;

- family carers' beliefs about their own need for support and assistance;

- family carers' interpretations of the behaviors of the people with dementia.

The interventions could be provided in a group or individual setting. No restrictions with regard to types of control interventions (usual care or placebo intervention) have been made.

\section{Types of outcome measures}

The outcomes were divided into the following.

1. Psychological morbidity and distress of the family carers, including depression and anxiety.

2. Quality of life of the family carers.

3. Family carers' appraisal of their role performance including burden, coping and self-efficacy, and appraisal of problem behaviors.

4. Healthcare utilisation outcomes of the person with dementia, including admission to residential care or number of general practice visits. 


\section{Search methods for identification of studies}

The trials were identified from a search of the Cochrane Dementia and Cognitive Improvement Group Specialized Register on 5 April 2009. This register contains records from the following major healthcare databases: The Cochrane Library, MEDLINE, EMBASE, PsycINFO, CINAHL and LILACS; and many ongoing trial databases and other grey literature sources. For more detailed information on what the Group's specialized register contains, and to view the search strategies used to retrieve records, see the Cochrane Dementia and Cognitive Improvement Group methods used in reviews.

The Cochrane Library, MEDLINE, EMBASE, PsycINFO, CINAHL, LILACS and a number of trial registers and grey literature sources were also searched separately on 5 April 2009. The search strategies used to identify relevant controlled trials for this review can be found in Appendix 1.

\section{Data collection and analysis}

\section{Selection of studies}

Two review authors (MVD, ID) screened titles and abstracts and eliminated those clearly not relevant to this review. When the title and abstract did not provide all the information concerning the criteria, full paper copies were retrieved and screened. Authors of studies were contacted when additional information was required to assess whether the studies met the criteria for inclusion. Three review authors (MVD, ID and JMcC) screened the remaining studies for their eligibility and discussed them in accordance with the above defined criteria. Any disagreements about the selection of a trial were resolved by consensus. For one study, no agreement could be reached. Therefore, this study was independently assessed by Professor Linda Teri, acting as a contact editor of the Cochrane Dementia and Cognitive Improvement Group. Reasons for excluding any trial are detailed in the 'Characteristics of excluded studies'. Trials were not assessed blind as we knew the author's name and institution and the source of publication.

\section{Data extraction and management}

We extracted data from published reports using a standard form. The data used to measure outcomes in clinical trials of dementia and cognitive impairment were often ordinal. Where the rating scales used in the trials had a reasonably large number of categories (four or more) the data were treated as continuous and arising from a normal distribution. Summary statistics (n, mean and standard deviation) were required for continuous outcomes, for both the treatment and the control groups in each trial. Where possible, the outcomes were changes from baseline.
When change from baseline results were not reported, we calculated the required summary statistics from the baseline and assessment time group means and standard deviations, assuming a 0.4 correlation between the measurements at baseline and follow-up assessment. This method overestimates the standard deviation of the change from baseline. Such a conservative approach is preferable in a meta-analysis (http://ims.cochrane.org/revman/ documentation/rm5userguide.pdf). The baseline assessment is defined as the latest available assessment prior to randomisation, but no longer than two months prior. For dichotomous outcomes, the number with the outcome of interest, such as institutionalization, was extracted for the treatment and control groups.

For each outcome measure, we sought data on every patient randomised. To allow an intention-to-treat analysis, the data were sought irrespective of compliance and whether or not the patient was subsequently deemed ineligible or otherwise excluded from treatment or follow-up.

\section{Assessment of risk of bias in included studies}

\section{Quality assessment}

The internal validity of trials is related to how successfully selection, performance, attrition and detection biases are eliminated. The methodological quality of the included studies was assessed and reported according to the methods set out in section 7 of the Cochrane Handbook for Systematic Reviews of Interventions (Higgins2009), which recommends the evaluation of selection bias, performance bias, detection bias and attrition bias. Each source of potential bias was assessed with respect to the following quality elements: randomisation, sequence generation and baseline comparability (selection bias); blinding of participants or providers, or both (performance bias); blinding of outcome assessors (detection bias); reporting of attrition rate, and the use of intention-to-treat analyses (attrition bias). Each parameter of trial quality was graded: A (adequate); B (unclear); C (inadequate). In most quality rating scales blinding is evaluated on several levels, such as blinding of patients and therapists or care providers. These scales are often used to test the quality of placebo-controlled medication studies. However, it is nearly impossible to blind the participants in a psychosocial intervention trial to the intervention to which they have been assigned and obviously impossible to blind the therapists to the intervention that they are delivering, but detection bias can be prevented by blinding of outcome assessors. Thus, blinding of patients and therapists was not included as one of the quality criteria but blinding of outcome assessors was included.

Two review authors (MVD, ID) and a research assistant (FB) independently assessed the methodological quality of the selected studies. One review author (ID) and a research assistant (FB) extracted the data, checked for discrepancies and processed the data 
as described in Higgins 2005 (Higgins 2005). All studies were included in the initial analysis and if at risk of bias then excluded in the sensitivity analysis.

\section{Process analysis}

In practice, compliance with the intervention protocol might be problematic. The specific intervention activities and the actual exposure of the therapists and patients to these activities may influence results and effectiveness (Hulscher 2003). Therefore we also assessed whether or not a process analysis had been performed (Hulscher 2003).

\section{Measures of treatment effect}

Meta-analysis requires the combination of data from trials that may not use the same rating scale or test to assess an outcome. To accommodate this heterogeneity, the measure of the treatment difference for any outcome was the weighted mean difference when the pooled trials used the same scale, and the standardised mean difference (the absolute mean difference divided by the standard deviation) when they used different scales. For binary outcomes such as institutionalization or no institutionalization, we used either the odds ratio or the risk difference to measure treatment effect and calculated a weighted estimate of the typical treatment effect across trials.

\section{Unit of analysis issues}

The level at which the randomisation occurs must be taken into account. In most circumstances the number of observations will match the number of 'units' that were randomised. Cluster randomised trials were only considered if the reported analysis correctly accounted for the clustering. If a trial included repeated measurements, then care was taken not to include multiple measurements from the same trial in a single analysis. For crossover trials, only data from the first treatment period were included.

\section{Dealing with missing data}

When changes from baseline results were not reported, we calculated the required summary statistics from the baseline and assessment time treatment group means and standard deviations. In this case we assumed a 0.4 correlation between the measurements at baseline and assessment time.

\section{Assessment of heterogeneity}

Heterogeneity refers to the variability among the studies included in the systematic review. We considered heterogeneity among participants (for example age and relationship with patient), interventions and outcomes. As these factors varied between studies, they may affect the study effects. We performed tests for heterogeneity using a standard $\mathrm{Chi}^{2}$ statistic and an $\mathrm{I}^{2}$ statistic. Studies were considered heterogeneous if $\mathrm{P} \leq 0.05$. In general, this meant $\mathrm{I}^{2}>50 \%$.

\section{Assessment of reporting biases}

The extent of publication bias was to be assessed through visual inspection of asymmetry. All studies were included in the initial analysis and then excluded in sensitivity analyses if at risk of bias.

\section{Data synthesis}

We presented overall estimates of the treatment difference. In all cases our aim was to present the overall estimate from a fixed-effect model. Where there was substantial heterogeneity of the treatment effect between trials $\left(\mathrm{I}^{2}>50 \%\right)$ then we either: 1$)$ pooled only homogeneous results; or 2) used a random-effects model (in which case the confidence intervals would be wider than those of a fixedeffect model).

\section{Subgroup analysis and investigation of heterogeneity}

Analyses of groups of different types of participants distinguished in the included studies were reported. Since most psychosocial intervention studies had low numbers of participants, it was not possible to extract sufficient comparable data to undertake a meaningful subgroup analysis.

\section{Sensitivity analysis}

As stated in Module 14 of the Cochrane Collaboration open learning material (http://www.cochrane-net.org/openlearning/ HTML/mod14-2.htm), sensitivity analyses involved comparing the results of two or more meta-analyses calculated using different assumptions in order to assess the robustness of the results to the method used. The assumptions may concern a study's poorer quality, doubtful eligibility, outlier studies, imputed missing information, size of the trial, etc. We performed sensitivity analysis where in doubt.

\section{RE S U L T S}

\section{Description of studies}

See: Characteristics of included studies; Characteristics of excluded studies.

Eleven trials were identified that met inclusion criteria. See the 'Characteristics of included studies'. 


\section{Participants}

Participants were family carers of people with dementia. Family carers' ages ranged from 19 to 84 years; the average age was 59 years. The relationship to the person with dementia was spouse (40.2\%), adult child (28.1\%) and other (6.7\%). For $25 \%$ of the carers no relationship to the person with dementia was specified.

\section{Interventions and theoretical models used}

The included studies used the following theoretical models: the stress coping model (Beauchamp 2005; Farran 2007; Hebert 2003; Hepburn 2005), the stress management model (Zarit 1987) and the cognitive behavioral therapy (CBT) model (Akkerman 2004; Chang 1999; Coon 2003; Gallagher-Thompson 2007; MarquezGonzalez 2007; Marriott 2000).

In the stress coping model, individuals faced with a stressor make two appraisals, referred to as the primary and secondary appraisal. The primary appraisal involves an assessment of how stressful or threatening the situation is. The secondary appraisal involves the individual's assessment of his or her ability to cope, including an assessment of personal and physical resources. This secondary appraisal is often equated to Bandura's concept of self-efficacy (Bandura 1977). Once an individual has appraised the situation, he or she then employs his or her coping skills. These coping skills can include emotion-focused approaches (for example avoidance, magical thinking), problem-focused strategies (changing behaviors), and utilization of social support systems. According to the stress coping model (Lazarus 1984), the application of coping skills results in an outcome that prompts new appraisals, sparks new applications of skills, and so on. In this way coping is conceptualized not as a static event but as a process that unfolds in a cyclic pattern.

In the stress management model, treatment is oriented toward changing specific aspects of the carer situation that have been linked with carer stress, namely increasing their understanding of the patient's disease, improving their management of problem behaviors, and helping them to identify and use more informal and formal supports.

Process analysis or intervention dosage has been conducted by a few authors, which indicates whether the intervention has actually been carried out as intended. Only Chang 1999 (registration of telephone call) and Zarit 1987 (a supervision meeting in which an audiotape of a session with a caregiver was reviewed) reported process analyses.

Outcome measures

\section{Anxiety}

The interventions based on CBT typically include cognitive reframing as part of the intervention. In this context, the cognitive reframing element focuses on family carers' maladaptive, selfdefeating or distressing cognitions about their relatives' behaviors and their own performance in the caring role. It aims to alter these cognitions directly, making them better adapted to the situation. The differences in the theories underlying these three approaches are minor. CBT is the most structured model. The CBT interventions were psycho-educational in nature and included: targeted skill training (teaching, and helping carers to practise distinct selfmanagement skills) (Coon 2003); skills to cope with caring stress (Gallagher-Thompson 2007); cognitive behavioral family intervention (Marriott 2000); modification of dysfunctional thoughts about care (Marquez-Gonzalez 2007) and didactic training skills to address physical, cognitive and behavioral components (Akkerman 2004).

The interventions based on the stress coping model included: web-based, multi-media interventions such as interactive videos (Beauchamp 2005), a video-assisted modeling program with a cognitive and a behavior modeling aspect (Chang 1999), a programme to improve caregivers' ability to cope with sources of stress associated with caring (Hebert 2003), targeted skill building (Farran 2007) and psycho-education (Hepburn 2005). The intervention based on the stress management model used family counselling and support groups (Zarit 1987).

\section{Risk of bias in included studies}

All included studies were randomised controlled trials, but the randomisation technique was only mentioned by three authors (Hebert 2003; Hepburn 2005; Marriott 2000). Baseline data were compared in all studies except in Zarit 1987. As argued earlier, performance bias is difficult to prevent in psychosocial intervention trials but detection bias can be prevented by blinding of outcome assessors. This was reported in nearly $50 \%$ of the studies. The attrition rate was reported in nearly all studies. Intention-totreat analysis was rarely used. The results are shown in Table 1.

1. State-Trait Anxiety Inventory (STAXI) asks participants how anxious they feel 'right now' by using a 4-point Likert scale, from 3 (very much) to 0 (not at all).

2. The Hamilton Anxiety Scale (HAMA) is a clinician-rated interview used to assess the presence or absence of symptoms associated with anxiety. The measure contains 14 separate interview items evaluating the level of anxiety experienced over the past month through the use of a 5-point severity scale (i.e. none, mild, moderate, severe, and very severe; range 0 to 56).

3. The Brief Symptom Inventory (BSI) (Derogatis 1982) is composed of 53 items that assess the frequency with which subjects have experienced various psychiatric symptoms during 
the previous seven days. Each item of the BSI is rated on a 5point scale of distress (0 to 4), ranging from 'not-at-all' to 'extremely'. The anxiety subscale was used.

\section{Depression}

1. The Center for Epidemiological Studies Depression scale (CES-D) (Radloff1977) is a 20-item self-report measure that assesses the frequency of depressive symptoms (affective, psychological, and somatic) in the past week through the use of a 4-point scale. The scores range from 0 to 60 . Lower scores indicate fewer depressive complaints.

2. The Multiple Affect Adjective Checklist (MAACL) Depression subscale (Zuckerman 1965) consists of a list of 132 positive and negative mood adjectives. Participants read the list and select those descriptive of how they have felt in the past week. Examples of Hostility subscale items include 'mad', 'disagreeable', and 'tender'; and examples of Depression subscale items include 'sad', 'blue', and 'happy'.

3. Beck Depression Inventory (BDI) (Beck1988) consists of 21 items assessing depression through a 4-point scale (range 0 to 63); the total score is derived.

4. BSI (see above), the depression subscale was used.

\section{Stress}

1. Revised Burden Interview (BI) (Zarit 1982): the BI consists of 22 items that assess the caregiver's perception of the impact the involvement with the patient has had on his or her own life. Prior studies have demonstrated good reliability and validity of this instrument (Zarit 1982).

2. 10-item Perceived Stress Scale, derived from the 14-item scale (Cohen1983), measures overall appraisals of stress in the past month. It has been psychometrically tested and used in many studies with family carers of people with dementia. It assesses how unpredictable, uncontrollable, and overloaded respondents find their lives. Items are rated on 5-point Likert scales (0: never, and 4: very often).

3. Two studies (Beauchamp 2005; Hepburn 2005) used investigator-developed stress or distress scales.

\section{Carer burden}

1. The Zarit Burden Interview (Zarit 1985), also referred to as the Revised Burden Interview (BI) (Zarit 1982), is a 22-item scale measuring the subjective load experienced by the caregiver by asking him or her how frequently ( 0 : never, to 4 : almost always) they feel various emotions in their relationship with their relative with dementia, for a total score out of 88 . Scores between 8 and 17 represent a moderate burden, scores between 18 and 32 represent high burden, and scores over 32 represent severe burden. This measure provides a direct assessment of the carer's appraisal of the impact that caring for their relative has had on his or her life.

2. Caregiver Strain Instrument was developed by the Benjamin Rose Research Institute (Bass 1998). Fourteen selfreport questions begin with the stem "During the past 4 weeks, because of helping the patient, I felt ...." Responses include items that assess carer health, relationship strain, and mastery of skills on a 5-point Likert scale, with answers ranging from 5 (strongly agree) to 0 (strongly disagree).

\section{Coping or self-efficacy}

1. The Ways of Coping Checklist-Revised (WCCL-R) (Vitaliano 1985). This measure produces subscales that reflect use of different coping strategies: 'Problem Solving', 'Count Your Blessings', 'Support Focused', 'Avoidance', 'Wishful Thinking', 'Blame Self', 'Blame Others', and 'Religious Coping'. The 'Positive Coping' subscale was used in the Coon 2003 study and 'Coping-total' in the Beauchamp 2005 study.

2. Ways of Coping. Caregiver coping was assessed using the 48-item coping scale (Moos 1992). The scale measures different types of coping, with eight subscales that measure approach (problem-solving) or avoidance (emotion-focused) coping responses. Higher scores indicate more frequent use of the response. Internal consistency in the present study was 0.77 for the total scale, 0.68 for problem-focused, and 0.65 for emotionfocused coping.

3. Caregiving Competence (Pearlin 1990). Caregivers responded to six brief scales reporting on their own perceptions of relational deprivation, role captivity, loss of self, caregiving competence, management of meaning, and caregiving mastery (the data are not reported for the last scale).

\section{Revised Memory and Behavior Problem Checklist (RMBPC-reaction)}

1. The Revised Memory and Behavior Problem Checklist, developed by Teri 1992, measures the frequency of behavioral and memory problems, and the reactions that these problems generate in the informal carer. The 24 items describe behaviors and participants score their frequency during the preceding week (on a scale from 0: never to 4: every day) and the extent to which this problem disturbed or upset them (on a scale from 0: not at all to 4: extremely).

\section{Quality of life}

Although several instruments have been developed to assess quality of life, these measures were not used in the included studies. 


\section{Healthcare utilization}

For outcomes of the person with dementia, including residential care or number of general practice visits. The only healthcare utilization outcome in the included studies for the person with dementia was institutionalisation.

\section{Effects of interventions}

Analyses were performed on the combined results of the trials, except for the healthcare utilization outcomes.

\section{Anxiety}

The combined results from the included trials (Akkerman 2004; Beauchamp 2005; Chang 1999; Hebert 2003) reporting change in anxiety indicated a significant benefit from treatment (standardised mean difference (SMD) $-0.21 ; 95 \%$ confidence interval (CI) -0.39 to -0.04 ) in reducing anxiety (Figure 1 ).

Figure I. Forest plot of comparison: Anxiety

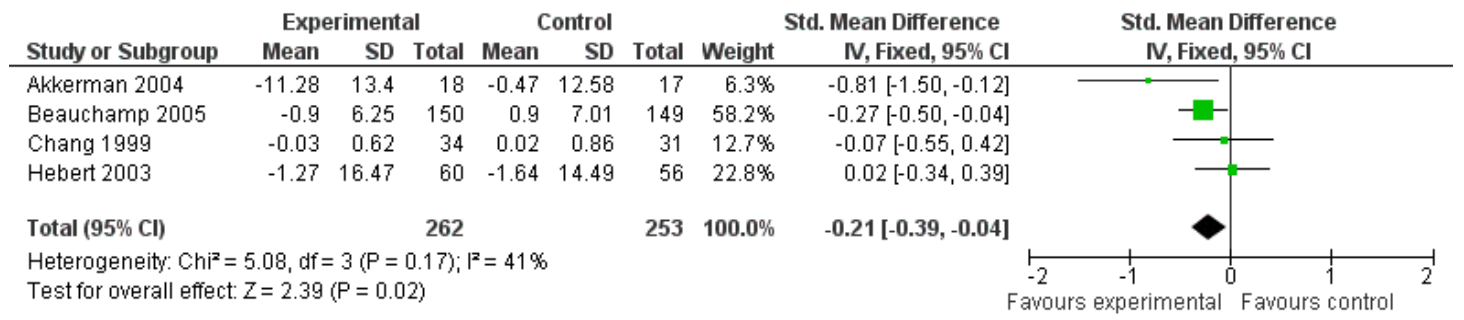

\section{Depression}

The combined results from the included trials (Beauchamp 2005; Chang 1999; Coon 2003; Gallagher-Thompson 2007; Marquez-Gonzalez 2007; Marriott 2000) reporting change in depression indicated a significant benefit from treatment (SMD 0.66; $95 \%$ CI -1.27 to -0.05 ) in reducing depression (Figure 2). There was considerable heterogeneity between the trials, with Coon's study showing the highest effect size but all studies favoring the intervention group. Therefore, we performed a subgroup analysis without the Coon 2003 study. The heterogeneity effect disappeared $\left(\mathrm{Chi}^{2}=2.53, \mathrm{df}=4, \mathrm{P}=0.64, \mathrm{I}^{2}=0 \%\right)$ while the intervention effect remained significant (SMD -0.24; 95\% CI 0.42 to -0.07$)$.

Figure 2. Forest plot of comparison: Depression.

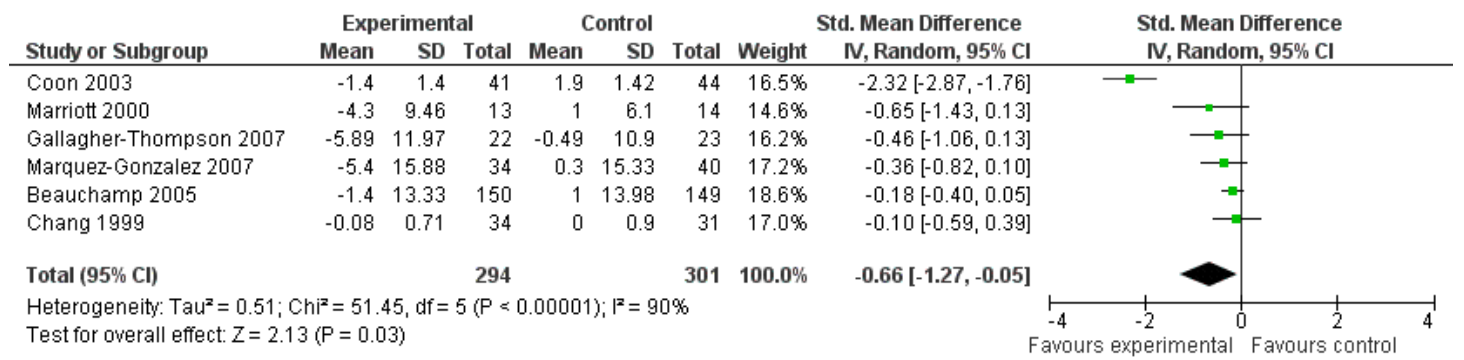




\section{Carer burden}

Neither the combined result nor the individual studies ( Beauchamp 2005; Hebert 2003; Hepburn 2005; Zarit 1987) showed a significant benefit from treatment in reducing burden (SMD -0.14; 95\% CI -0.32 to 0.03) (Figure 3).

Figure 3. Forest plot of comparison: Burden.

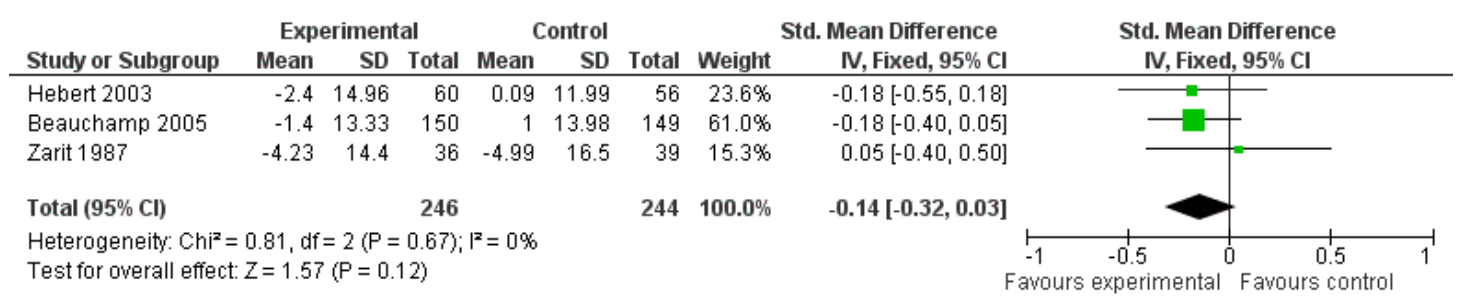

\section{Coping or self-efficacy}

The combined results from the included trials (Beauchamp 2005; Chang 1999; Coon 2003; Hepburn 2005) showed no significant benefit from treatment on coping or self-efficacy (SMD 0.64; $95 \%$ CI -0.17 to 1.45 ) (Figure 4).

Figure 4. Forest plot of comparison: Coping and self-efficacy.

\begin{tabular}{|c|c|c|c|c|c|c|c|c|c|c|}
\hline \multirow[b]{2}{*}{ Study or Subgroup } & \multicolumn{3}{|c|}{ Experimental } & \multicolumn{3}{|c|}{ Control } & \multicolumn{2}{|c|}{ Std. Mean Difference } & \multirow{2}{*}{\multicolumn{2}{|c|}{$\begin{array}{c}\text { Std. Mean Difference } \\
\text { IV, Random, } 95 \% \mathrm{Cl}\end{array}$}} \\
\hline & Mean & SD & Total & Mean & SD & Total & Weight & IV, Random, 95\% Cl & & \\
\hline Beauchamp 2005 & 1 & 12.4 & 150 & 1 & 14 & 149 & $26.2 \%$ & $0.00[-0.23,0.23]$ & & \\
\hline Hepburn 2005 & 0.17 & 0.59 & 120 & 0.15 & 0.63 & 46 & $25.6 \%$ & $0.03[-0.31,0.37]$ & & \\
\hline Chang 1999 & 3.54 & 6.77 & 32 & 0.5 & 8.32 & 31 & $24.3 \%$ & $0.40[-0.10,0.90]$ & & \\
\hline Coon 2003 & 3.9 & 2.02 & 41 & -0.5 & 1.9 & 44 & $23.9 \%$ & $2.23[1.68,2.77]$ & & . \\
\hline Total $(95 \% \mathrm{Cl})$ & & & 343 & & & 270 & $100.0 \%$ & $0.64[-0.17,1.45]$ & & \\
\hline \multicolumn{9}{|c|}{$\begin{array}{l}\text { Heterogeneity: } \text { Tau }^{2}=0.64 ; \mathrm{Chi}^{2}=56.81, \mathrm{df}=3(\mathrm{P}<0.00001) ;\left.\right|^{2}=95 \% \\
\text { Test for overall effect: } Z=1.54(P=0.12)\end{array}$} & $\begin{array}{cccc}1 & 1 & 1 & 1 \\
-2 & -1 & 0 & 1 \\
\text { Favours control } & \text { Favours ex }\end{array}$ & $\begin{array}{c}2 \\
2 \\
\text { experi }\end{array}$ \\
\hline
\end{tabular}

\section{Stress or distress related to caregiving}

The combined results from the included trials (Beauchamp 2005; Gallagher-Thompson 2007; Hepburn 2005; Zarit 1987) reporting change in stress or distress indicated a significant benefit from treatment (SMD -0.24; 95\% CI -0.40 to -0.07) (Figure 5). 
Figure 5. Forest plot of comparison: Stress or distress.

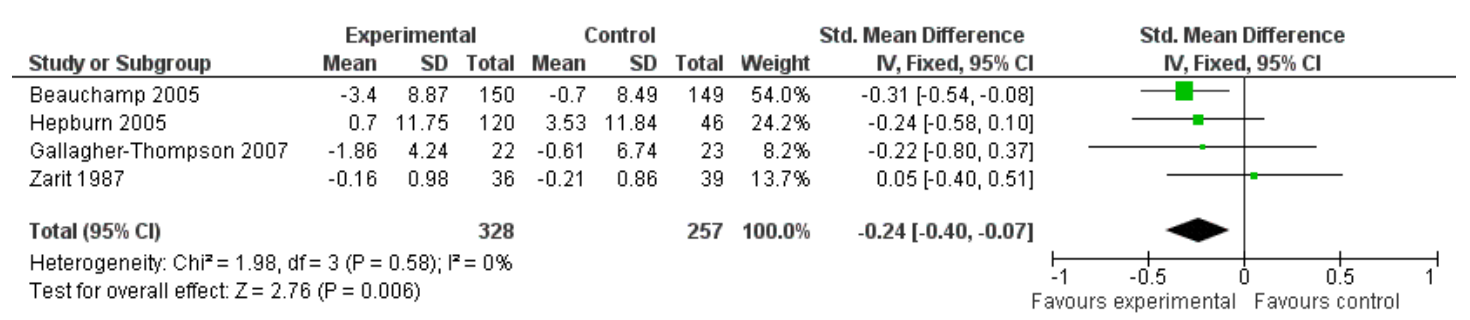

\section{RMBPC-reaction Revised Memory and Behavior Problem Checklist (RMBPC-reaction)}

The combined results from the included trials (Hebert 2003; Marquez-Gonzalez 2007; Zarit 1987) showed no significant benefit from treatment in RMBPC-reaction (SMD -0.21; 95\% CI 0.45 to 0.03 ) (Figure 6).

Figure 6. Forest plot of comparison: RMBPC-reaction.

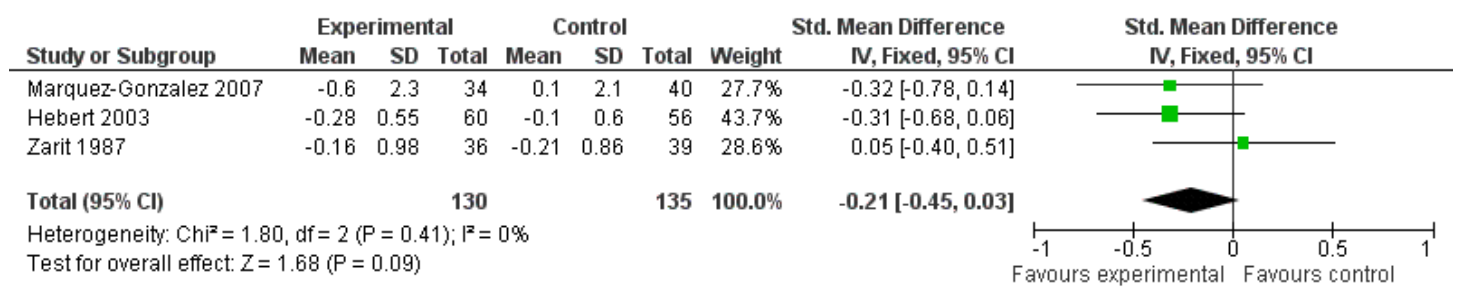

\section{Institutionalization}

The only available measure of healthcare utilization was institutionalization, and this appeared in only one study. No significant results of cognitive reframing on institutionalization were found.

\section{DISCUSSION}

This systematic review and meta-analysis of cognitive reframing for family carers of persons with dementia showed beneficial effects over usual care for psychological morbidity (anxiety, depression) and (dis)stress. No effects were found for coping or self-efficacy, carer burden, reaction to the relative's behavior and institutionalization.

Consistent with our hypothesis, a positive effect on psychological morbidity was found. This is in accordance with the findings of
Gale 2000. In contrast to our hypothesis, there is no evidence for the impact of cognitive reframing on burden or reaction to the relative's behavior, nor on coping or self-efficacy.

Focusing on the trials using a specific component of psychosocial interventions, in this case cognitive reframing, contributes to our knowledge of how psychosocial interventions work. Our data support the general cognitive reframing model, showing positive effects on psychological morbidity and (dis)stress. Our data help us to refine the results of other reviews which indicated that interventions producing positive effects generally are tailor-made and multi-component (Brodaty 2003; Spijker 2008) by suggesting the use of cognitive reframing as a valuable component in dealing with psychological morbidity and stress.

While process analysis could be used to examine how cognitive reframing interventions are actually used, and point to factors which prompt or impede their use, in the studies reviewed there was little evidence of process analyses having been conducted. 
Ensuring the validity of trials examining the effectiveness of psychosocial interventions poses a greater challenge than ensuring the validity of pharmacological trials. There is a greater risk of contamination in psychosocial research as patients in the control group may become informed about the intervention and its content and be influenced by this information. The inclusion of studies using intention-to-treat analyses does not take into account the effect of attrition. It is useful to report findings from both the intention-totreat analysis and analysis for just those people who were exposed to the intervention.

Following our inclusion criteria strictly, we excluded the study of Whitlatch 1995 in which participants were differentiated by baseline scores, and more positive results were found. The different results arose because the investigators in this study ran analyses including only people who demonstrated significant levels of depression and burden at baseline. When participants who do not show significant levels of depression and burden are also included, there is less potential for the intervention to improve these outcomes.

Since there are several limitations to this review, our conclusions should be treated with caution. Although the quality of the studies is mainly satisfactory, as yet blinding of the assessor and intentionto-treat analysis are not common practice in psychosocial research. The number of included participants is modest, as is the number of included studies. Therefore, we might have missed true differences between subgroups. Heterogeneity exists regarding the participants' demographics (for example spouse or adult child carers), types of dementia in patients, intervention delivery methods, and outcome measures. However, the relatively low numbers of participants did not permit conclusions about differential effectiveness regarding relevant subgroups such as spousal and non-spousal carers.

The selection of studies remains a major issue for this review. None of the retrieved studies were specifically trials of cognitive reframing and selection of the studies for inclusion involved an element of subjective judgment about trials in which identifying and modifying participants' relevant beliefs was a specific, main aim of the intervention. We attempted to minimize this by having three authors assess the studies independently against a careful definition of 'cognitive reframing' and by having an external arbitrator de- cide in cases of disagreement. However, we acknowledge that some of the excluded multi-component studies may have used similar components.

The most important strength of the present review is the homogeneity of the theoretical framework across the selected trials; all included studies utilized cognitive reframing as the main component in their intervention, be it informed by the stress coping model, the stress management model or the CBT model.

\section{A U THOR S' CONCLUSIONS Implications for practice}

In clinical practice, cognitive reframing could be a useful additional tool in individualised support for carers of people with dementia. Cognitive reframing is individualised in the sense that it focuses on the personal attributions of the carer and stimulates personal change in appraisals. Although potentially influenced by many factors, a carer's change in appraisals is ultimately a personal process. Its individualised nature makes cognitive reframing applicable to a variety of caring situations and problems.

\section{Implications for research}

The present review adds further refinement to these conclusions in that it points to cognitive reframing as an effective underlying mechanism for reducing informal caregivers' psychological morbidity and stress. We hypothesize that cognitive reframing operates primarily through carers' attributions about personal strength and resilience. In future research this hypothesis can be empirically tested, thereby contributing to a systematic accumulation of knowledge on the mechanisms of action underlying psychosocial interventions. A challenge for future research is to further refine methodologies for trials of psychosocial interventions, including controlled designs with a lower risk of contamination.

\section{ACKNOWLEDGEMENTS}

Frederike Brouwer (FB) for her assistance in data gathering and assessment of methodological quality. 


\section{R E F E R E N C E S}

\section{References to studies included in this review}

Akkerman 2004 \{published data only\}

Akkerman RL, Ostwald SK. Reducing anxiety in Alzheimer's disease family caregivers: the effectiveness of. American Journal of Alzheimer's Disease and Other Dementias 2004;19 (2):117-23.

Beauchamp 2005 \{published data only\} Beauchamp N, Irvine AB, Seeley J, Johnson B. Worksitebased internet multimedia program for family caregivers of persons with dementia. Gerontologis 2005;45(6):793-801.

Chang 1999 \{published data only\}

Chang BL. Cognitive-behavioural intervention for homebound caregivers of persons with dementia. Nursing Research 1999;48:173-82.

Coon 2003 \{published data only\}

Coon DW, Thompson L, Steffen A, Sorocco K, Gallagher Thompson D. Anger and depression management: psychoeducational skill training interventions for women caregivers of a relative with dementia. The Gerontologist 2003;43(5):678-89.

Farran 2007 \{published data only\} Farran CJ, Gilley DW, McCann, JJ, Bienias JL, Lindemann DA, Evans DA. Efficacy of behavioral interventions for dementia caregivers. Western Journal of Nursing Research 2007;29(8):944-60.

Gallagher-Thompson 2007 \{published data only\} Gallagher-Thompson D, Gray Hl, Tang PCY, Pu CY, Leung LYL, Wang P, et al.Impact of in-home behavioral management versus telephone support to reduce depressive symptoms and perceived stress in Chinese caregivers: Results of a pilot study. American Journal of Geriatric Psychiatry 2007;15(5):425-34.

Hebert 2003 \{published data only\} Hebert R, Levesque L, Vezina J, Lavoie JP, Ducharme F, Gendron C, et al.Efficacy of a psychoeducative group program for caregivers of demented persons living at home: a randomized controlled trial. Journal of Gerontology. Series B, Psychological Sciences and Social Sciences 2003;58(1): S58-67.

Hepburn 2005 \{published data only\} Hepburn KW, Lewis M, Narayan S, Center B, Tornatore J, Bremer KL, Kirk LN. Partners in caregiving: a psychoeducation program affecting dementia family caregivers' distress and caregiving outlook. Clinical Gerontologist 2005;29(1):53-69.

Marquez-Gonzalez 2007 \{published data only\} Márquez-González M, Losada A, Izal M, Pérez-Rojo G, Montorio I. Modification of dysfuntional thoughts about caregiving in dementia family caregivers: Description and outcomes of an intervention programme. Aging \& Mental Health 2007;11(6):616-25.
Marriott 2000 \{published data only\}

Marriott A, Donaldson C, Tarrier N, Burns A. Effectiveness of cognitive-behavioural family intervention in reducing the burden of carers of patients with Alzheimer's disease. British Journal of Psychiatry 2000;176:557-62.

Zarit 1987 \{published data only\}

Zarit SH, Anthony CR, Boutselis M. Interventions with caregivers of dementia patients: Comparison of two approaches. Psychology and Aging 1987;2(3):225-32.

\section{References to studies excluded from this review}

Belle 2006 \{published data only\}

Belle SH, Burgio L, Burns R, Coon D, Czaja SJ, GallagherThompson D, et al.Enhancing the quality of IIfe of dementia caregivers from different ethnic or racial groups: A randomized, controlled trial. Annals of Internal Medicine 2006;145(10):727-38.

Boyle 2004 \{published data only\}

Boyle PA, Malloy PF, O'Connor M, Carruth S, Green RC, et al.Evaluating the efficacy of a caregiver-based, behavioral intervention for reducing neuropsychiatric symptoms among patients with Alzheimer's disease and for reducing caregiver distress: A controlled trial. Neurobiology of Aging 2004;25 Suppl 2:329.

Brennan 1995 \{published data only\}

Brennan PF, Moore SM, Smyth KA. The effects of a special computer network on caregivers of persons with Alzheimer's disease. Nursing Research 1995;44(3):166-72.

Brodaty 1989 \{published data only\}

Brodaty $\mathrm{H}$, Gresham M. Effect of a training programme to reduce stress in carers of patients with dementia. BMJ 1989; 299(6712):1375-8.

Brodaty 1997 \{published data only\}

Brodaty H, Gresham M, Luscombe G. The Prince Henry Hospital dementia caregivers' trainings programme. International Journal of Geriatric Psychiatry 1997;12: 183-92.

Brodaty2003 \{published data only\}

Brodaty H, Green A, Koschera A. Meta-analysis of psychosocial interventions for caregivers of people with dementia. Journal of the American Geriatrics Society 2003; 51:657-64.

Buchanan 2004 \{published data only\} Buchanan J. Generalization of the effects of a cognitivebehavioral intervention for family caregivers of individuals with dementia. Dissertation 2004.

Buckwalter 1999 \{published data only\}

Buckwalter KC, Gerdner L, Kohout F, Hall GR, Kelly A, Richards B, Sime M. A nursing intervention to decrease depression in family caregivers of persons with dementia. Archives of Psychiatric Nursing 1999;8(2):80-8. 
Burgener 1998 \{published data only\}

Burgener SC, Bakas T, Murray C, Dunahee J, Tossey S. Effective caregiving approaches for patients with Alzheimer's disease. Geriatric Nursing 1998;19(3):121-6.

Burgio 2003 \{published data only\} Burgio L, Stevens A, Guy D, Roth DL, Haley WE. Impact of two psychosocial interventions on white and African American family caregivers of individuals with dementia. The Gerontologist 2003;43(4):568-79.

Burns 2003 \{published data only\} Burns R, Nichols LO, Martindale-Adams J, Graney MJ, Lummus A. Primary care interventions for dementia caregivers: 2-Year outcomes from the REACH study. The Gerontologist 2003;43(4):547-55.

Burns 2005 \{published data only\}

Burns A, Guthrie E, Marino-Francis F, Busby C, Morris J, Russell E, et al.Brief psychotherapy in Alzheimer's disease: Randomised controlled trial. British Journal of Psychiatry 2005;187(2): 143 .

\section{Chapman 2004 \{published data only\}}

Chapman SB, Weiner MF, Rackley A, Hynan LS, Zientz $\mathrm{J}$. Effects of cognitive-communication stimulation for Alzheimer's disease patients treated with donepezil. Journal of Speech, Language, and Hearing Research 2004;47: 1149-63.

Chu 2000 \{published data only\}

Chu P EJ, Thomson J. The use of clinical case management for early stage Alzheimer's patients and their families. American Journal of Alzheimer's Disease 2000;15:284-90.

Coles-Gale 2002 \{published data only\}

Coles-Gale B, Byrne L. Spaull D, Emmerson C, Hyde J. Group non-directive support os psycho education in early cognitive impairment: a phenomenological comparison of group process and content. The 8th International Conference on Alzheimer's Disease and Related Disorders. 2002.

Done 2001 \{published data only\}

Done DJ, Thomas JA. Training in communciation skills for informal carers of people suffering from dementia: a cluster randomized clinical trial comparing a therapist led workshop and booklet. International Journal of Geriatric Psychiatry 2001;16:816-21.

\section{Droes 2000 \{published data only\}}

Droes RM, Breebaart E, Ettema TP, van Tilburg W, Mellenbergh GJ. Effect of integrated family support versus day care only on behavior and mood of patients with dementia. International Psychogeriatrics 2000;12:99-115.

Drummond 1991 \{published data only\} Drummond MF, Mohide EA, Tew M, Streiner DL, Pringle DM, Gilbert JR. Economic evaluation of a support program for caregivers of demented elderly. International Journal of Technology Assessessment in Health Care 1991;7:209-19.

Dye 1999 \{published data only\}

Dye JF. The impact of validation thearpy on family caregivers of cognitively impaired older adults. Dissertation abstracts International Section B The Sciences and Engineering 1999.

Eloniemi 2001 \{published data only\} Eloniemi-Sulkava U, Notkola I, Hentinen M, Kivelä S, Sivenius J, Sulkava R. Effects of supporting communityliving demented patients and their caregivers: A randomized trial. Journal of the American Geriatric Society 2001;49: 1282-7.

Fung 2002 \{published data only\}

Fung W, Chien W. The effectiveness of a mutual support group for family caregivers of a relative with dementia. Archives of Psychiatric Nutrsing 2002;6(3):134-44.

Gallagher-Th 1994 \{published data only\} Gallagher-Thompson D, Steffen AM. Comparative effects of cognitive-behavioral and brief psychodynamic psychotherapies for depressed family caregivers. Journal of Consulting and Clinical Psychology 1994;62(3):543-9.

Gallagher-Thompson 2003 \{published data only\} Gallagher-Thompson D, Coon DW, Solano N, Ambler C, Rabinowitz Y, Thompson LW. Change in indices of distress among Latino and Anglo female caregivers of elderly relatives with dementia: Site-specific results from the Reach National Collaborative Study. The Gerontologist 2003;43 (4):580-91.

Gaugler 2008 \{published data only\} Gaugler JE, Roth DL, Haley WE, Mittelman MA. Can counseling and support reduce burden and depressive symptoms in caregivers of people with Alzheimer's disease during the transition to institutionalization? Results from the New York University caregiver intervention study. Journal of the American Geriatrics Society 2008;56(3):421-8.

Gendron 1996 \{published data only\}

Gendron C, Poitras L, Dastoor DP, Perodeau G. Cognitivebehavioral group intervention for spousal caregivers: Findings and clinical considerations. Clinical Gerontologist 1996;17(1):3-19.

Gerdner 2002 \{published data only\}

Gerdner LA, Buckwalter KC, Reed D. Impact of a psychoeducational intervention on caregiver response to behavioral problems. Nursing Research 2002;51(6):363-74.

Gitlin 2002 \{published data only\}

Gitlin L. Using the home environment to support family caregivers. Proceedings of the 8th International Conference on Alzheimer's Disease and Related Disorders. Stockholm, 2002.

Gitlin 2005 \{published data only\}

Gitlin LN, Hauck WW, Dennis MP, Winter L. Maintenance of effects of the Home Environmental Skill-Building Program for family caregivers and individuals with Alzheimer's disease and related disorders. Journal of Gerontology: Medical Sciences 2005;60A(3):368-74.

Gitlin 2008 \{published data only\} Gitlin LN, Winter L, Burke J, Chernett N, Dennis MP, Hauck WW. Tailored activities to manage neuropsychiatric behaviors in persons with dementia and reduce caregiver 
burden: a randomized pilot study. American Journal of

Geriactric Psychiatry 2008;16(3):229-39.

Goodman 1990 \{published data only\}

Goodman CC, Pynoos J. A model telephone information and support program for caregivers of Alzheimer's patients.

The Gerontologist 1990;30(3):399-404.

Graff 2007 \{published data only\}

Graff MJL, Adang EMM, Vernooij-Dassen MJM, Dekker J, Jönsson L, Thijssen M, et al.Community occupational therapy for older patients with dementia and their care givers: cost effectiveness study. BMJ 2008;336:134-8.

Hebert 1994 \{published data only\}

Hébert R, Leclerc G, Bravo G, Girouard D, Lefrancois R. Efficacy of a support group programme for caregivers of demented patients in the community: a randomized controlled trial. Archives of Gerontology and Geriatrics 1994; 18:1-14.

Lopez 2008 \{published data only\}

Lopez J, Crespo M. Analysis of the efficacy of a psychotherapeutic program to improve the emotional status of caregivers of elderly dependent relatives. Aging \& Mental Health 2008;12(4):451-61.

\section{Lovett \{published data only\}}

Lovett S, Gallagher D. Psychoeducational interventions for family caregivers: Preliminary efficacy data. Behavior Therapy 1988;19:321-30.

\section{Lowery \{published data only\}}

Lowery K. A pilot study to compare group cognitive therapy and education in carers of dementia sufferers. National Research Register 1999.

Macdonald 1999 \{published data only\}

Macdonald A. RCT of telephone deemntia carer support. Current Controlled Trials 1999.

Mahoney 2003 \{published data only\}

Mahoney DF, Tarlow BJ, Jones RN. Effects of an automated telephone support system on caregiver burden and anxiety: Findings from the REACH for TLC Intervention Study. The Gerontologist 2003;43(4):556-67.

Martin-Carrasco 2008 \{published data only\}

Martı n-Carrasco M, Martı n MF, Pelegn n Valero C, Millan PR, Gara a CI, Montalban SR, et al.Effectiveness of a psychoeducational intervention program in the reduction of caregiver burden in Alzheimer's disease patients' caregivers. International Journal of Geriatric Psychiatry 2009; 24:489-99.

Martin-Cook 2000 \{published data only\}

Martin-Cook, Trimmer K, Svetlik C, Weiner D, Myron F. Caregiver burden in Alzheimer's disease: Case studies. American Journal of Alzheimer's Disease and Other Dementias 2000; 15:47-52.

McClendon 1998 \{published data only\} McClendon MJ, Bass DM, Brennan PF, McCarthy C. A computer network for Alzheimer's caregivers and use of support group services. Journal of Mental Health and Aging 1998;4:403-20.
Mittelman 1993 \{published data only\}

Mittelman MS, Ferris SH, Steinberg G, Shulman E, Mackell JA, Ambinder A, Cohen J. An intervention that delays institutionalization of Alzheimer's disease patients: treatment of spouse-caregivers. The Gerontologist 1993;33: $730-40$.

Mittelman 1996 \{published data only\}

Mittelman MS, Ferris SH, Shulman. Support for caregivers delayed time to nursing home placement in Alzheimer disease. ACP Journal Club 1997;126:67.

Mittelman 2004 \{published data only\}

Mittelman MS, Roth DL, Coon DW, Haley WE. Sustained benefit of supportive intervention for depressive symptoms in caregivers of patients with Alzheimer's disease. American Journal of Psychiatry 2004;161:850-6.

Mittelman 2006 \{published data only\} Mittelman MS, Haley WE, Clay OJ, Roth DL. Improving caregiver well-being delays nursing home placement of patients with Alzheimer disease. Neurology 2006;67(9): 1592-9.

Mittelman 2007 \{published data only\} Mittelman MS, Roth DL, Clay OJ, Haley WE. Preserving Health of Alzheimer Caregivers: Impact of a Spouse Caregiver Intervention. American Journal of Geriatric Psychiatry 2007;15(9):780-789.

Mittelman 2008 \{published data only\} Gitlin LN, Winter L, Burke J, Chernett N, Dennis MP, Hauck WW. Tailored activities to manage neuropsychiatric behaviors in persons with dementia and reduce caregiver burden: a randomized pilot study. American Journal of Geriatric Psychiatry 2008;16(3):229-39.

Mohide 1990 \{published data only\}

Mohide EA, Pringle DM, Streiner DL, Gilbert JR, Muir G, Tew M. A randomized trial of family caregivers support in the home management of dementia. Journal of the American Geriatrics Society 1990;38(4):446-54.

Mohide 1992 \{published data only\} Mohide EA. Evaluating the effectiveness of a multyfaceted community-based support program. Unknown 1992.

Mohide et al.1993 \{published data only\} Mohide EA, Streiner DL. Depression in caregivers of impaired elderly family members. Unknown 1993.

Narayan 2000 \{published data only\}

Narayan SM, Hepburn KW, Lewis ML, Corcoran-Perry SA. Decision-making-focused education as a mediator of family caregiving stress. Proceedings of the World Alzheimer Congress, Washington DC. 2000.

Newcomer 1997 \{published data only\}

Newcomer R, Spitalny M, Fox P, Yordy C. Effects of the Medicare Alzheimer's disease demonstration on the use of community-based services. Health Services Research 1999; 34:645-67.

Nichols 2005 \{published data only\}

Nichols LO. Testing the effectiveness of telephone support for dementia caregivers. ClinicalTrials.Gov 2005. 
Nobili 2004 \{published data only\}

Nobili A, Riva E, Tettamanti M, Lucca U, Liscio M, Petrucci B, Porro GS. The effect of a structured intervention on caregivers of patients with dementia and problem behaviors: A randomized controlled pilot study. Alzheimer Disease and Associated Disorders 2004;18:75-82.

Olshevski 1999 \{published data only\}

Olshevski JL, Katz AD, Knight BG. The effectiveness of teh stress reductiuon technique. Stress Reduction for Caregivers. Philadelphia: Brunner/Mazel, 1999:99-115.

Ostwald 1999 \{published data only\} Ostwald SK, Hepburn KW, Caron W, Burns T, Mantell. Reducing caregiver burden: a randomized psychoeducational intervention for caregivers of persons with dementia. Gerontologist 1999;39(3):299-309.

Perraud 2004 \{published data only\} Perraud S, Farran CJ, Loukissa D, Paun O. Alzheimer's disease caregiving information and skills, part III: Group process issues and concerns. Research in Nursing \& Health 2004;27:110-20.

Pillemer 2002 \{published data only\}

Pillemer K, Suitor J. Peer support for Alzheimer's caregivers: Is it enough to make a difference?. Research on Aging 2002; 24:171-92.

Quayhagen 2000 \{published data only\} Quayhagen MA, Quayhagen M, Corbeil RR, Hendrix RC, Jackson JE, Snyder L, Bower D. Coping with dementia: Evaluation of four nonpharmacologic interventions. International Psychogeriatrics 2000;12(2):249-65.

Roberts 1999 \{published data only\} Roberts J, Browne G, Milne C, Spooner L, Gafni A, Drummond-Young $\mathrm{M}$, et al.Problem-solving counseling for caregivers of the cognitively impaired: effective for whom. Nursing Research 1999;48(3):162-72.

Robinson 1994 \{published data only\} Robinson K, Yates K. Effects of two caregiver-training programs on burden and attitude toward help. Archives of Psychiatric Nursing 1994;8(5):312-9.

Seltzer 1992 \{published data only\} Seltzer MM, Litchfield LC, Kapust LR, Mayer JB. Professional and family collaboration in case management: a hospital-based replication of a community-based study. Social Work in Health Care 1992;17:1-22.

Shaji 2001 \{published data only\}

Shaji KS, Praveenlal K. Information and education for carers of patients with Alzheimer's disease. British Journal of Psychiatry 2001;178:83-4.

Steffen 2000 \{published data only\} Steffen AM. Anger management for dementia caregivers: A preliminary study using video and telephone interventions. Behavior Therapy 2000;31(2):281-99.

Stevens 2004 \{published data only\} Stevens AB, Coon D, Wisniewski S, Vance D, Arguelles S, Belle $S$, et al.Measurement of leisure time satisfaction in family caregivers. Aging \& Mental Health 2004;8:450-9.
Teri 1994 \{published data only\}

Teri L. Behavioral treatment of depression patients with dementia. Alzheimer Disease and Associated Disorders 1994; 8 Suppl 3:66-74.

Teri 1998 \{published data only\}

Teri L, Logsdon RG, Whall AL, Weiner MF, Trimmer C, Peskind E, et al.Treatment for agitation in dementia patients: A behavior management approach. Psychotherapy 1998;35(4):436-43.

Thompson 2001/a \{published data only\}

Thompson DG. Measurement of leisure time satisfaction in family caregivers. Proceedings of the 14th Annual Meeting of the American Association for Geriatric Psychiatry. San Francisco, 2001.

Vernooij-Dassen 2000a \{published data only\} Vernooij-Dassen MJFJ, Lamers C, Bor H, Grol RPTM. Prognostic factors of effectiveness of a support program for caregivers of dementia patients. International Journal of Aging and Human Development 2000;51(4):259-74.

Walton 1994 \{published data only\}

Walton CF. Effects of an informational support strategy on levels of perceived stress for primary family caregivers of Alzheimer's patients. Clemson University 1994.

Whitlatch 1991 \{published data only\}

Whitlatch CJ, Zarit SH, von Eye A. Efficacy of interventions with caregivers: a reanalysis. The Gerontologist 1991;31: 9-14.

Whitlatch 1995 \{published data only\} Whitlatch CJ, Zarit SH, Goodwin PE, von Eye A. Influence of the success of psychoeducational interventions on the course of family care. Clinical Gerontologist 1995;16(1): $17-30$.

Winter 2006 \{published data only\} Winter L, Gitlin LN. Evaluation of a telephone-based support group intervention for female caregivers of community-dwelling individuals with dementia. American Journal of Alzheimer's Disease and Other Dementias 2007;21: 391.

Zimmer 1990 \{published data only\} Zimmer JG, Eggert GM, Chiverton P. Individual versus team case management in optimizing community care for chronically ill patients with dementia. Journal of Aging and Health 1990;2:357-72.

\section{Additional references}

\section{Bandura 1977}

Bandura A. Self-efficacy: towards a unifying theory of behavioral change. Psychological Review 1977;94(3): 191-215.

\section{Bass 1998}

Bass DM, McLClendon MJ, Flatley- Brennan P, McCarthy C. The buffering effect of a computer support network on caregiver strain. Journal of Aging and Health 1998;10: $20-43$. 


\section{Beck1988}

Beck AT, Epstein N, Brown G, Steer RA. An inventory for measuring clinical anxiety: Psychometric properties. Journal of Consulting and Clinical Psychology 1988;56:893-7.

\section{Blumer 1969}

Blumer H. Symbolic Interactionism. Englewood Cliffs: Prentice Hall, 1969.

\section{Brodaty 2003}

Brodaty H, Green A, Koschera A. Meta-analysis of psychosocial interventions for caregivers of people with dementia. Journal of the American Geriatrics Society 2003. 51:657-64.

\section{Derogatis 1982}

Derogatis LR, Spencer PM. The Brief Symptom Inventory (BSI): Administration and procedures manual. Baltimore MD: John Hopkins University School of Medicine, Clinical Psychometric Research Unit, 1982.

\section{Draper 1992}

Draper BM, Poulos CJ, Cole AMD. A comparison of caregivers for edlerly stroke and dementia victims. Journal of the American Geriatrics society 1992;40:896-901.

\section{EuroCoDe 2009}

EuroCoDe. Dementia in Europe Yearbook 2009.

Luxembourg: Alzheimer Europe, 2009.

\section{Folkman 1991}

Folkman S, Chesney M, McKusick L, Ironson G, Johnson DS, Coates TJ. Translating coping theory into an intervention. In: J Eckenrode editor(s). The social context of coping. New York: Plenum Press, 1991:239-60.

\section{Gale 2000}

Gale C, Oakley-Browne M. Anxiety Disorder. Clinical review. BMJ 2000;321:1204-7.

\section{Higgins 2005}

Higgins J, Green S, editors. Cochrane Handbook for Systematic Reviews of Interventions. 4.2 .5 [updated May 2005].. The Cochrane Collaboration 2005. http:// www.cochrane.org/resources/handbook/hbook.htm, 2005.

\section{Higgins2009}

Higgins JPT, Green S. Cochrane Handbook for Systematic Reviews of Interventions. The Cochrane Collaboration. Vol. Version 5.0.2 [updated September 2009], Available from www.cochrane-handbook.org, 2009.

\section{Hulscher 2003}

Hulscher M, Laurant M, Grol R. Process evaluation on quality improvement interventions. Quality and Safety in Health Care 2003;12(1):40-6.

Joling 2010

Joling KJ, van Hout HP, Schellevis FG, Knol DL, van Marwijk HW. Incidence of depression and anxiety in the spouses of patients with dementia: a naturalistic cohort study of recorded morbidity with a 6-year follow-up. American Journal of Geriatric Psychiatry 2010;18(2):146-53.

\section{Lazarus 1984}

Lazarus RS, Folkman S. Stress, appraisal and coping. Stress, appraisal and coping. New York: Springer, 1984.

\section{Losada 2006}

Losada A, Montorio I, Izal M, Mórquez-González M. Study and intervention on dementia caregiving distress. The role of dysfunctional thoughts [Estudio e intervencián sobre el malestar psicolágico de los cuidadores de personas con demencia. El papel de los pensamietos disfuncionales.]. Madrid: IMSERSO. 2006.

\section{Machnicki 2008}

Machnicki G, Allegri RF, Dillon C, Cerrano CM, Taragano FE. Cognitive, functional and behavioral factors associated with the burden of caring for geriatric patients with cognitive impairment or depression: evidence from a South American sample. International Journal of Geriatric Psychiatry 2009;24(4):382-9.

\section{Moos 1992}

Moos, RH, Brennan, PL, Fondacaro, MR, Moos, BS. "Approach and avoidance coping responses among older problem and nonproblem drinkers": Clarification. Psychology and Aging 1992;7(4):653.

\section{Pearlin 1990}

Pearlin LI, Mullan JT, Semple SJ, Skaff MM. Caregiving and the stress process: an overview of concepts and their measures. Gerontologist 1990;30(5):583-94.

\section{Radloff1977}

Radloff LS. The CES-D scale: a self-report depression scale for research in the general population. Applied Psychological Measurement 1977;1:385-401.

\section{Spijker 2008}

Spijker A, Vernooij-Dassen M, Vasse E, Adang E, Wollersheim H, Grol R, Verhey F. Effectiveness of nonpharmacological interventions in delaying the institutionalization of patients with dementia: A metaanalysis. Journal of the American Geriatrics Society 2008;56 (6):1116-28

\section{Teri 1992}

Ter L, Truax P, Logsdon R, Uomoto J, Zarit S, Vitaliano PO. Assessment of behavioral problems in dementia: The revised memory and behavior problems checklist. Psychology and Aging 1992;7:622-31.

Tolin 2010

Tolin DF. Is cognitive-behavioral therapy more effective than other therapies? A meta-analytic review. Clinical Psychology Review 2010 Aug;30((6)):710-20.

van den Wijngaart 2007 van den Wijngaart MA, Vernooij- Dassen MJ, Felling AJ. The influence of stressors, appraisal and personal conditions on the burden of spousal caregivers of persons with dementia. Aging and Mental Health 2007;11(6):626-36.

\section{Vernooij-Dassen 1997}

Vernooij-Dassen M, Felling A, Persoon J. Predictors of change and continuity in home care for dementia patients. International Journal of Geriatric Psychiatry 1997;12(6): 671-7. 


\section{Vitaliano 1985}

Vitaliano PP, Russo J, Carr JE, Maiuro RD, Becker J.

The ways of coping checklist: Revision and psychometric properties. Multivariate Behavioral Research 1985;20:3-26.

\section{WHO 2008}

WHO. THE GLOBAL BURDEN OF DISEASE: 2004 update. WHO Library Cataloguing-in-Publication Data. Geneva: WHO Press, 2008

\section{Wimo 2007}

Wimo A, Winblad B, Jönsson L. An estimate of the total worldwide sociatal costs of dementia in 2005. Alzheimer's \& Dementia 2007;3(2):81-91.

\section{Zarit 1982}

Zarit SH, Zarit JM. Families under stress: Interventions for caregivers of senile dementia patients. Psychotherapy: Theory, Research and Practice 1982;19:461-71.

\section{Zarit 1985}

Zarit S, Orr N, Zarit J. The hidden victims of Alzheimer's disease: Families under stress. New York: New York University Press, 1985.

\section{Zuckerman 1965}

Zuckerman M, Lubin B. Manual for the Multiple Affect Adjective Check List. San Diego, CA: Educational and Industrial Testing Service, 1965.

* Indicates the major publication for the study 
CHARACTERISTICS OF STUDIES

Characteristics of included studies [ordered by study ID]

Akkerman 2004

\begin{tabular}{|c|c|}
\hline Methods & RCT \\
\hline Participants & $\begin{array}{l}\text { - } \mathrm{N}=38,86 \% \text { female } \\
\text { - Age } \mathrm{M}=58.1(\mathrm{SD}=13.8) \\
\text { - Drop out } \mathrm{N}=3(7.9 \%) \\
\text { - Duration of caregiving (years) } \mathrm{M}=3.6(\mathrm{SD}=2.09) \\
\text { - Hours caregiving per week } \mathrm{M}=111(\mathrm{SD}=59.4) \\
\text { - Referral through print media, brochures, online articles, community presentations, and paid radio announcement }\end{array}$ \\
\hline Interventions & $\begin{array}{l}\text { 1. CBT (cognitive-behavioural therapy). Didactic skills training using a multidimensional model to address physical, } \\
\text { cognitive and behavioural components associated with caregiver anxiety. Two-hour weekly meetings for } 9 \text { weeks } \\
\text { 2. Control: wait list }\end{array}$ \\
\hline Outcomes & $\begin{array}{l}\text { Anxiety (BAI) } \\
\text { Hamilton Anxiety Scale (HAMA) }\end{array}$ \\
\hline Notes & Treatment sessions in small groups: 4-8 caregivers. Follow-up: 10 weeks (post-intervention), $16 \mathrm{w}, 20 \mathrm{w}, 26 \mathrm{w}$ \\
\hline
\end{tabular}

\section{Beauchamp 2005}

\begin{tabular}{|c|c|}
\hline Methods & RCT \\
\hline Participants & $\begin{array}{l}\text { - } \mathrm{N}=299,73 \% \text { female, } 80 \% \text { caucasian, } 4 \% \text { african american, } 8 \% \text { hispanic and } 8 \% \text { other } \\
\text { - Age } M=46.9(\mathrm{SD}=12.2 \text {; range } 19.2-84.3) \\
\text { - Drop out } \mathrm{N}=8 \\
\text { - } 90 \% \text { completed college or trade school. } \\
\text { - } 33 \% \text { primary caregiver, } 27 \% \text { shared caregiving, } 40 \% \text { not primary caregivers } \\
\text { - } 67 \% \text { son or daughter, } 7 \% \text { spouse, } 23 \% \text { relative, } 3 \% \text { non-relative }\end{array}$ \\
\hline Interventions & $\begin{array}{l}\text { 1. Caregiver's Friend: Dealing With Dementia is a web-based multimedia intervention that provides text material } \\
\text { and videos that model positive caregiving strategies } \\
\text { 2. Control: usual care }\end{array}$ \\
\hline Outcomes & $\begin{array}{l}\text { Stress } \\
\text { Self-efficacy } \\
\text { Ways of coping } \\
\text { Caregiver strain } \\
\text { Depressive symptoms } \\
\text { State anxiety }\end{array}$ \\
\hline Notes & The stress and coping model by Lazarus and Folkman (1984) is used as theoratical basis. No process analysis \\
\hline
\end{tabular}




\section{Chang 1999}

\begin{tabular}{|c|c|}
\hline Methods & RCT \\
\hline Participants & $\begin{array}{l}\text { - } \mathrm{N}=65 ; 100 \% \text { female, } 79.1 \% \text { Caucasian Americans of European background, } 16.3 \% \text { African-American } \\
\text { - Age } \mathrm{M}=66.52(\mathrm{SD}=11.96) \\
\text { - Drop out } 25 \% \\
\text { - Duration caregiving (years) } \mathrm{M}=3.36(\mathrm{SD}=2.77) \\
\text { - Spouses: } 88.6 \% \\
\text { - Referral through Alzheimer associations, Alzheimer clinics and local support groups }\end{array}$ \\
\hline Interventions & $\begin{array}{l}\text { 1. Treatment group }(\mathrm{N}=34) \text { - } \mathrm{CBI} \text { - cognitive-behavioral intervention tailored to the specific deficits of persons } \\
\text { with dementia }(\mathrm{PWDs}) \text { : a. videotapes demonstrating assisted modeling behavior; b. nurse line support programme } \\
\text { to reinforce video information and to explore coping strategies } \\
\text { 2. Control group }(\mathrm{N}=31) \text { : attention only by telephone calls }\end{array}$ \\
\hline Outcomes & $\begin{array}{l}\text { Coping strategies scale (Moos 1992) } \\
\text { Somatic and emotional manifestations of depression, anxiety, and hostility - Brief Symptom Inventory (BSI) }\end{array}$ \\
\hline Notes & $\begin{array}{l}\text { Process analysis by registration of phone calls. } \\
\text { The study is conceptualised using the stress and coping framework of Lazarus and Folkman (Lazarus 1984). }\end{array}$ \\
\hline \multicolumn{2}{|l|}{ Coon 2003} \\
\hline Methods & RCT \\
\hline Participants & $\begin{array}{l}\text { - } \mathrm{N}=169 ; 100 \% \text { female } \\
\text { - Age } \mathrm{M}=6.7 \text { (SD 8.4) } \\
\text { - } 57 \% \text { spouse } \\
\text { - Drop out } 23 \% \text { (including institutionalisation) } \\
\text { - Duration of caregiving (months) } \mathrm{M}=40.7 \\
\text { - Referral through variety of means, clinical and non-clinical, including newspapers }\end{array}$ \\
\hline Interventions & $\begin{array}{l}\text { Anger management class, } \mathrm{N}=41 \\
\text { Depression management class, } \mathrm{N}=45 \\
\text { Wait-list control, } \mathrm{N}=44\end{array}$ \\
\hline Outcomes & $\begin{array}{l}\text { State anger (STAXI) } \\
\text { MAACL Hostility subscale } \\
\text { MAACL Depression subscale } \\
\text { Negative and Positive Coping: Self-efficacy, Managing behaviors, Controlling thoughts (WCCL-R) }\end{array}$ \\
\hline Notes & $\begin{array}{l}\text { The cognitive behavioral model is used. There was a 4-month follow-up period and control variables were used } \\
\text { No process analysis. }\end{array}$ \\
\hline
\end{tabular}


Farran 2007

\begin{tabular}{ll}
\hline Methods & RCT \\
\hline Participants & $-\mathrm{N}=143,82.5 \%$ female, $81.1 \%$ white, $18.9 \%$ black \\
& $\begin{array}{l}-51.8 \% \text { non-spouse and } 49.2 \% \text { spouse } \\
- \text { Participants were recruited from a variety of settings }\end{array}$ \\
\hline Interventions & $\begin{array}{l}\text { 1. Caregiver skill building treatment intervention } \\
\text { 2. Information and support oriented therapies }\end{array}$ \\
\hline Outcomes & $\begin{array}{l}\text { Distress with behavioral symptoms } \\
\text { Behavioral management skill }\end{array}$ \\
\hline Notes & $\begin{array}{l}\text { Group and individual telephone sessions were tape recorded and written summaries of all sessions were reviewed to } \\
\text { maintain treatment integrity }\end{array}$ \\
\hline
\end{tabular}

\section{Gallagher-Thompson 2007}

\begin{tabular}{|c|c|}
\hline Methods & RCT \\
\hline Participants & $\begin{array}{l}-\mathrm{N}=45 \\
\text { - Age } \mathrm{M}=59.33(\mathrm{SD}=12.23) \\
\text { - Drop out } \mathrm{N}=10 \\
\text { - Years of education } \mathrm{M}=13.42(\mathrm{SD}=20.93) \\
\text { - Years in the United States } \mathrm{M}=31.13(\mathrm{SD}=20.93) \\
\text { - } 14 \text { spouses and } 31 \text { non-spouses } \\
\text { - Duration of caregiving (months): } 1 \text {. TSC }(\mathrm{N}=23), \mathrm{M}=41.26(\mathrm{SD}=29.77), 2 \text {. IHBMP }(\mathrm{N}=22), \mathrm{M}=48.32(\mathrm{SD}= \\
42.86)\end{array}$ \\
\hline Interventions & $\begin{array}{l}\text { 1. IHBMP - In-home behavioral management program for } 4 \text { months is comprised of six modules that focus on } \\
\text { learning new skills to help the CG cope with caregiving stress: Introduction, Behavior management, Unhelpful } \\
\text { thoughts, Communication issues, End-of-life (EOL), Pleasant events } \\
\text { 2. TSC - the telephone support condition (comparison) }\end{array}$ \\
\hline Outcomes & $\begin{array}{l}\text { 1. Depressive symptoms, CES-D } \\
\text { 2. Perceived Stress Scale } \\
\text { 3. Conditional Bother Subscale (CBS) derived from the Revised Memory and Behavior Problems Checklist (RMBPC) } \\
\text { - } 24 \text { items describing possible troublesome behaviors that the CR might engage in (e.g. wandering) } \\
\text { 4. Self-efficacy. The revised self-efficacy scale (SE) is used, } 15 \text { items ( } 5 \text { on each subscale) measuring CGs' beliefs } \\
\text { about their ability to handle situations in three domains: 1) obtaining respite from caregiving burdens; 2) responding } \\
\text { effectively to disruptive behaviors; and 3) controlling upsetting thoughts while in the caregiving role }\end{array}$ \\
\hline Notes & No pr \\
\hline
\end{tabular}


Hebert 2003

\begin{tabular}{ll}
\hline Methods & RCT \\
\hline Participants & $-\mathrm{N}=118$; intervention group $\mathrm{N}=60(80.0 \%$ women $)$, control group $\mathrm{N}=58(81.0 \%$ women $)$ \\
& - Mean age 60 years \\
& - Drop out $\mathrm{N}=40$ \\
& - Years of education: 1 . intervention group $-\mathrm{M}=11.77(\mathrm{SD}=3.80), 2$. control group $\mathrm{M}=12.19(\mathrm{SD}=4.39)$ \\
& - Duration of caregiving: 1 . intervention group $\mathrm{M}=2.90(\mathrm{SD}=2.23), 2$. control group $\mathrm{M}=2.74(\mathrm{SD}=2.00)$ \\
& - Spouses: 1 . intervention group $61.7 \%$, control group $60.3 \%$ \\
\hline
\end{tabular}

Interventions 1. Experimental program aimed to improve the caregiver's ability to cope with the numerous daily sources of stress associated with caring for a person with dementia. Developed according to the Lazarus and Folkman (1984) transactional theory of stress and coping. It comprised two components: cognitive appraisal and coping strategies 2. Control group: referral to traditional support group Alzheimer Society

Outcomes $\begin{aligned} & \text { 1. Reactions to behavioral problems (RMBPC) frequency and upset } \\ & \text { 2. Burden } \\ & \text { 3. Psychological distress (Bradburn Revised Affect Scale) } \\ & \text { 4. Anxiety (STAI) } \\ & \text { 5. Personal efficacy (Bandura) }\end{aligned}$

Notes $\quad$ No control variables were used. Theory used: transactional model of stress and coping (Folkman 1991). No process analysis.

\section{Hepburn 2005}

\begin{tabular}{|c|c|}
\hline Methods & RCT \\
\hline Participants & $\begin{array}{l}\text { 1. Day-to-day group ( } \mathrm{N}=79): 77.2 \% \text { female; age } \mathrm{M}=65.2 \text { years; } 68.4 \% \text { of spouses are the primary caregiver } \\
\text { 2. Decision making group }(\mathrm{N}=72): 77.8 \% \text { female; age } \mathrm{M}=64.6 \text { years; } 61.2 \% \text { of spouses are the primary caregiver } \\
\text { 3. Control group }(\mathrm{N}=64) 71.9 \% \text { female; age } \mathrm{M}=69.7 \text { years; } 67.2 \% \text { of spouses are the primary caregiver } \\
\text { - Drop out } 20.9 \%\end{array}$ \\
\hline Interventions & $\begin{array}{l}\text { 1. Day-to-day session focuses on developing strategies for everyday caregiving } \\
\text { 2. Decision making session focuses on identifying and using values and preferences as a way to evaluate the options } \\
\text { available in everyday caregiving } \\
\text { 3. Control group }\end{array}$ \\
\hline Outcomes & Caregiver Distress Measure \\
\hline Notes & $\begin{array}{l}\text { The programme and distress measure are tied to a stress mediation framework (Lazarus 1984). } \\
\text { No process analysis. }\end{array}$ \\
\hline
\end{tabular}


Marquez-Gonzalez 2007

\begin{tabular}{|c|c|}
\hline Methods & RCT \\
\hline Participants & $\begin{array}{l}\text { - } \mathrm{N}=74 \\
\text { 1. Intervention group } \mathrm{N}=34,82.4 \% \text { female } \\
\text { - Age } \mathrm{M}=58.1(\mathrm{SD}=13.9) \\
\text { - Years of education } \mathrm{M}=10.6(\mathrm{SD}=6.3) \\
\text { - Duration of caregiving (months) } \mathrm{M}=52.8(\mathrm{SD}=45.6) \\
\text { - } 55.3 \% \text { spouse; } 40 \% \text { son, } 6.7 \% \text { other relative } \\
\text { 2. Wait list control group }(\mathrm{N}=40), 77.5 \% \text { female } \\
\text { - Age } \mathrm{M}=55.4(\mathrm{SD}=15.9) \text {; } \\
\text { - Years of education } \mathrm{M}=9.2(\mathrm{SD}=4.8) \\
\text { - Duration of caregiving (months) } \mathrm{M}=49.0(\mathrm{SD}=29.5) \\
\text { - } 43.6 \% \text { spouse, } 51.3 \% \text { son, } 5.1 \% \text { other relative }\end{array}$ \\
\hline Interventions & $\begin{array}{l}\text { 1. MDTC - Modification of Disfunctional Thoughts associated with Caregiving (CBT-based) } \\
\text { 2. Waiting list control group (WL) }\end{array}$ \\
\hline Outcomes & $\begin{array}{l}\text { Depression } \\
\text { Frequency of behavioural problems } \\
\text { Apppraisal of behavioural problems (transformed) } \\
\text { Dysfunctional thoughts about caregiving }\end{array}$ \\
\hline Notes & $\begin{array}{l}\text { No process analysis. } \\
\text { Based on the CBT (cognitive behavioral therapy) adapted to the experience of caregiving model (Losada 2006). }\end{array}$ \\
\hline
\end{tabular}

\section{Marriott 2000}

\begin{tabular}{|c|c|}
\hline Methods & Prospective single blind RCT \\
\hline Participants & $\begin{array}{l}\text { - } \mathrm{N}=42,69 \% \text { female } \\
\text { - Age: } 1 \text {. no interview control group }(\mathrm{N}=14), \mathrm{M}=58.1(\mathrm{SD}=16.7), 2 \text {. interview control group }(\mathrm{N}=14), \mathrm{M}=63.0(\mathrm{SD}= \\
\text { 14.0), intervention group }(\mathrm{N}=14), \mathrm{M}=69.6(\mathrm{SD}=15.2) \\
\text { - } 53 \% \text { spouse, } 40 \% \text { child } \\
\text { - Drop out } 45 \% \\
\text { - Referral through old age psychiatry service }\end{array}$ \\
\hline Interventions & $\begin{array}{l}\text { 1. Family intervention: in depth interview (CFI) and cognitive behavioral family intervention } \\
\text { 2. Control } 1 \text { in depth interview } \\
\text { 3. Control } 2 \text { no intervention }\end{array}$ \\
\hline Outcomes & 2. Depression (BDI) \\
\hline Notes & $\begin{array}{l}\text { Treatment: } 14 \text { sessions, two weeks interval, follow-up period } 9 \text { months and } 12 \text { months; no control variables used. } \\
\text { Use of theoretical model (Tarrier et al 1988). Single blinded study. No process analysis }\end{array}$ \\
\hline
\end{tabular}


Zarit 1987

\begin{tabular}{|c|c|}
\hline Methods & RCT \\
\hline Participants & $\begin{array}{l}\text { - } \mathrm{N}=184 \\
\text { - Age } \mathrm{M}=62.2(\mathrm{SD}=12.8) \\
\text { - Years of education } \mathrm{M}=14.38(\mathrm{SD}=2.69) \\
-28 \% \text { wife, } 24 \% \text { husband, } 35 \% \text { daughters, } 6 \% \text { sons, } 7 \% \text { others } \\
\text { - } 80 \% \text { co-resident } \\
\text { - Drop out } 36 \% \\
\text { - Referral through local agencies and newspapers }\end{array}$ \\
\hline Interventions & $\begin{array}{l}\text { 1. Family counselling }(\mathrm{N}=36) \\
\text { 2. Support groups }(\mathrm{N}=44) \\
\text { 3. Wait list }(\mathrm{N}=39) \\
\text { Both treatment groups use stress management model: information, problem solving, identifying potential support }\end{array}$ \\
\hline Outcomes & $\begin{array}{l}\text { 1. Burden Interview (ZBI) } \\
\text { 2. Distress (MBPC) } \\
\text { 3. BSI-total } \\
\text { 4. Management of patient's behaviours (MBPC) upset }\end{array}$ \\
\hline Notes & 8 Sessions. Process analysis by audiotapes and supervision sessions \\
\hline
\end{tabular}

\section{Characteristics of excluded studies [ordered by study ID]}

\begin{tabular}{ll}
\hline Study & Reason for exclusion \\
\hline Belle 2006 & Multi-component intervention \\
\hline Boyle 2004 & Unobtainable \\
\hline Brennan 1995 & Intervention does not involve cognitive reframing \\
\hline Brodaty 1989 & Dataset used in other included study \\
\hline Brodaty 1997 & Multi-component intervention \\
\hline Brodaty2003 & No RCT \\
\hline Buchanan 2004 & Unobtainable \\
\hline Buckwalter 1999 & Intervention does not involve cognitive reframing \\
\hline Burgener 1998 & Incomplete and inadequate format data \\
\hline Burgio 2003 & Multi-component intervention \\
\hline
\end{tabular}


(Continued)

\begin{tabular}{|c|c|}
\hline Burns 2003 & Multi-component intervention \\
\hline Burns 2005 & Intervention does not involve cognitive reframing \\
\hline Chapman 2004 & No suitable outcomes \\
\hline Chu 2000 & Intervention does not include cognitive reframing \\
\hline Coles-Gale 2002 & No RCT \\
\hline Done 2001 & Intervention does not involve cognitive reframing \\
\hline Droes 2000 & No suitable outcomes \\
\hline Drummond 1991 & Intervention does not include cognitive reframing \\
\hline Dye 1999 & Unobtainable \\
\hline Eloniemi 2001 & Intervention does not involve cognitive reframing \\
\hline Fung 2002 & Intervention does not involve cognitive reframing \\
\hline Gallagher-Th 1994 & Not meeting inclusion criteria for participants \\
\hline Gallagher-Thompson 2003 & Multi-component intervention \\
\hline Gaugler 2008 & Multi-component intervention \\
\hline Gendron 1996 & Multi-component intervention \\
\hline Gerdner 2002 & Intervention does not involve cognitive reframing \\
\hline Gitlin 2002 & Unobtainable \\
\hline Gitlin 2005 & Intervention does not involve cognitive reframing \\
\hline Gitlin 2008 & Multi-component intervention \\
\hline Goodman 1990 & Intervention does not include cognitive reframing \\
\hline Graff 2007 & Multi-component intervention \\
\hline Hebert 1994 & Multi-component intervention \\
\hline Lopez 2008 & Multi-component intervention \\
\hline Lovett & Not meeting inclusion criteria for participants \\
\hline
\end{tabular}


(Continued)

\begin{tabular}{|c|c|}
\hline Lowery & Unobtainable \\
\hline Macdonald 1999 & Unobtainable \\
\hline Mahoney 2003 & Intervention does not involve cognitive reframing \\
\hline Martin-Carrasco 2008 & Multi-component intervention \\
\hline Martin-Cook 2000 & Unobtainable \\
\hline McClendon 1998 & No suitable outcomes \\
\hline Mittelman 1993 & Multi-component intervention \\
\hline Mittelman 1996 & Multi-component intervention \\
\hline Mittelman 2004 & Multi-component intervention \\
\hline Mittelman 2006 & Multi-component intervention \\
\hline Mittelman 2007 & Multi-component intervention \\
\hline Mittelman 2008 & Multi-component intervention \\
\hline Mohide 1990 & Intervention does not involve cognitive reframing \\
\hline Mohide 1992 & Unobtainable \\
\hline Mohide et al.1993 & Unobtainable \\
\hline Narayan 2000 & Unobtainable \\
\hline Newcomer 1997 & Intervention does not include cognitive reframing \\
\hline Nichols 2005 & Intervention does not include cognitive reframing \\
\hline Nobili 2004 & Intervention does not involve cognitive reframing \\
\hline Olshevski 1999 & Unobtainable \\
\hline Ostwald 1999 & Multi-component intervention \\
\hline Perraud 2004 & Intervention does not include cognitive reframing \\
\hline Pillemer 2002 & No suitable outcomes \\
\hline Quayhagen 2000 & Multi-component intervention \\
\hline
\end{tabular}


(Continued)

\begin{tabular}{|c|c|}
\hline Roberts 1999 & Unobtainable \\
\hline Robinson 1994 & Multi-component intervention \\
\hline Seltzer 1992 & Intervention does not include cognitive reframing \\
\hline Shaji 2001 & No RCT \\
\hline Steffen 2000 & Unobtainable \\
\hline Stevens 2004 & Unobtainable \\
\hline Teri 1994 & No RCT \\
\hline Teri 1998 & No RCT \\
\hline Thompson 2001/a & No suitable outcomes/unobtainable \\
\hline Vernooij-Dassen 2000a & Multi-component intervention \\
\hline Walton 1994 & Unobtainable \\
\hline Whitlatch 1991 & No RCT \\
\hline Whitlatch 1995 & No RCT \\
\hline Winter 2006 & Multi-component intervention \\
\hline Zimmer 1990 & Intervention does not include cognitive reframing \\
\hline
\end{tabular}


DATA AND ANALYSES

Comparison 1. Outcomes of cognitive reframing interventions

\begin{tabular}{lccll} 
Outcome or subgroup title & $\begin{array}{c}\text { No. of } \\
\text { studies }\end{array}$ & $\begin{array}{c}\text { No. of } \\
\text { participants }\end{array}$ & \multicolumn{1}{c}{ Statistical method } & Effect size \\
\hline 1 Anxiety & 4 & 515 & Std. Mean Difference (IV, Fixed, 95\% CI) & $-0.21[-0.39,-0.04]$ \\
2 Depression & 6 & 595 & Std. Mean Difference (IV, Random, 95\% CI) & $-0.66[-1.27,-0.05]$ \\
3 Burden & 3 & 490 & Std. Mean Difference (IV, Fixed, 95\% CI) & $-0.14[-0.32,0.03]$ \\
4 Coping/self efficacy & 4 & 613 & Std. Mean Difference (IV, Random, 95\% CI) & $0.64[-0.17,1.45]$ \\
5 stress/distress & 4 & 585 & Std. Mean Difference (IV, Fixed, 95\% CI) & $-0.24[-0.40,-0.07]$ \\
6 RMBPC-reaction & 3 & 265 & Std. Mean Difference (IV, Fixed, 95\% CI) & $-0.21[-0.45,0.03]$ \\
\hline
\end{tabular}

\section{Analysis I.I. Comparison I Outcomes of cognitive reframing interventions, Outcome I Anxiety.}

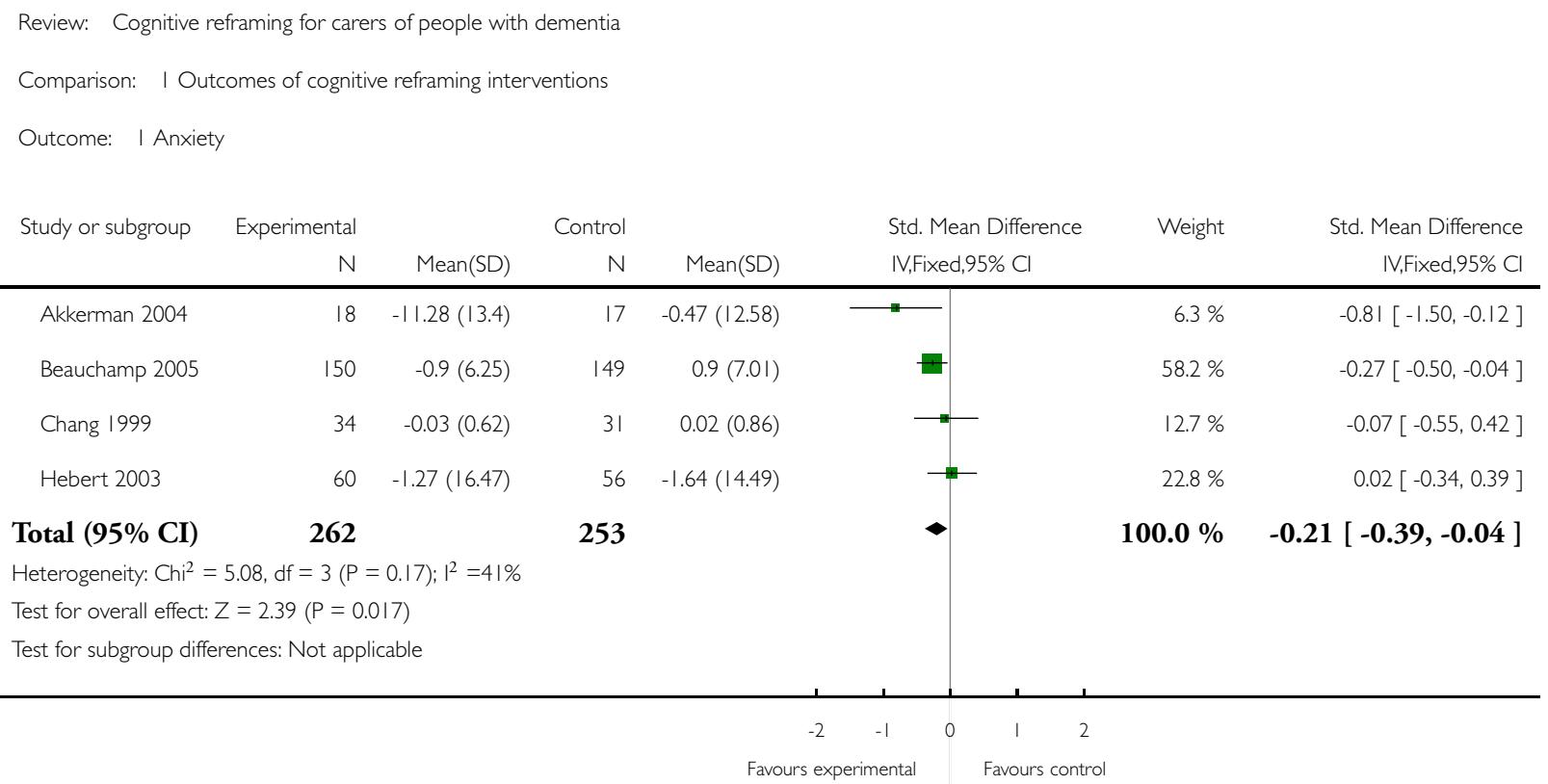


Analysis I.2. Comparison I Outcomes of cognitive reframing interventions, Outcome 2 Depression.

Review: Cognitive reframing for carers of people with dementia

Comparison: I Outcomes of cognitive reframing interventions

Outcome: 2 Depression

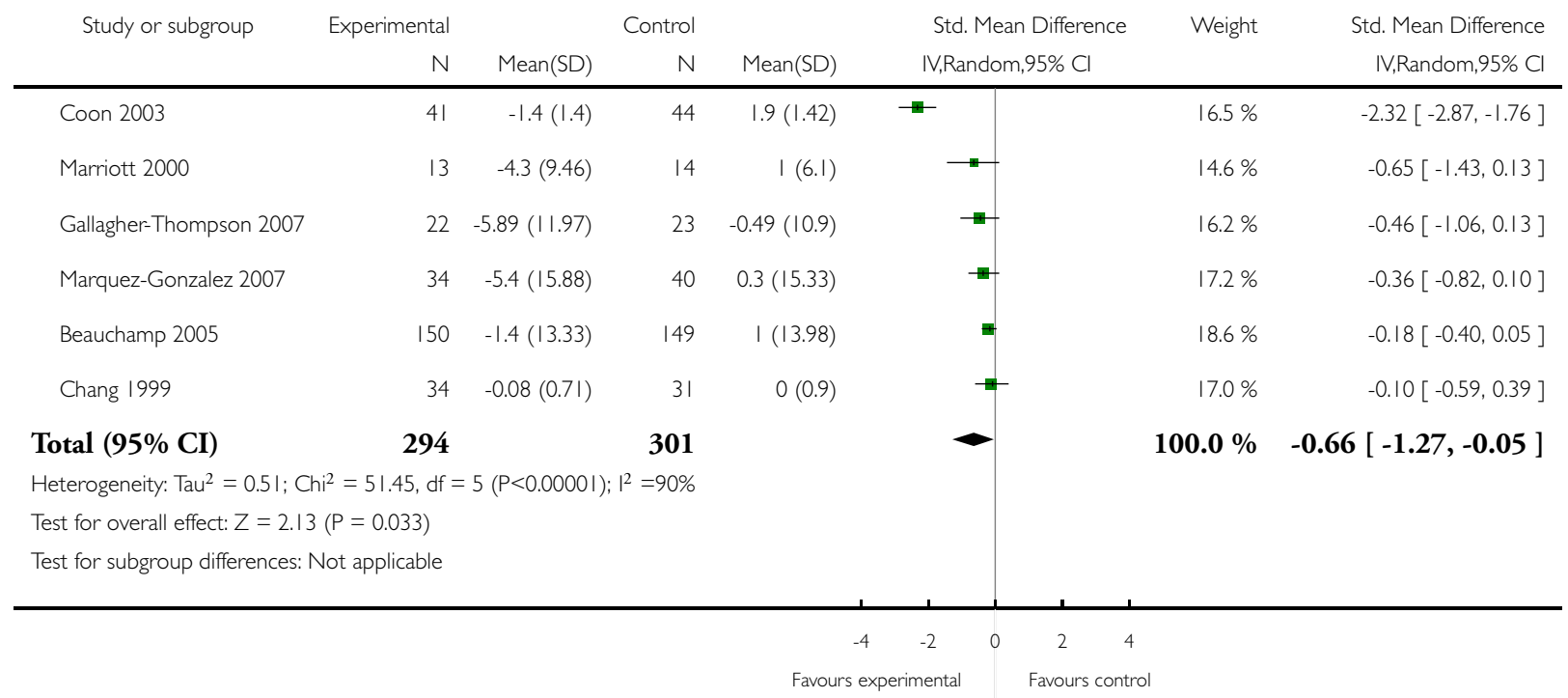

\section{Analysis I.3. Comparison I Outcomes of cognitive reframing interventions, Outcome 3 Burden.}

Review: Cognitive reframing for carers of people with dementia

Comparison: I Outcomes of cognitive reframing interventions

Outcome: 3 Burden

\begin{tabular}{|c|c|c|c|c|c|c|c|}
\hline \multirow[t]{2}{*}{ Study or subgroup } & Experimental & & Control & & Std. Mean Difference & Weight & Std. Mean Difference \\
\hline & $N$ & Mean(SD) & $\mathrm{N}$ & Mean(SD) & IV,Fixed,95\% Cl & & IV,Fixed,95\% Cl \\
\hline Hebert 2003 & 60 & $-2.4(14.96)$ & 56 & $0.09(11.99)$ & $\longrightarrow$ & $23.6 \%$ & $-0.18[-0.55,0.18]$ \\
\hline Beauchamp 2005 & 150 & $-1.4(13.33)$ & 149 & I (13.98) & 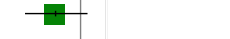 & $61.0 \%$ & $-0.18[-0.40,0.05]$ \\
\hline Zarit 1987 & 36 & $-4.23(14.4)$ & 39 & $-4.99(16.5)$ & 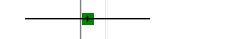 & $15.3 \%$ & $0.05[-0.40,0.50]$ \\
\hline
\end{tabular}

Total (95\% CI)

246

244

$100.0 \%$

$-0.14[-0.32,0.03]$

Heterogeneity: $\mathrm{Chi}^{2}=0.8 \mathrm{I}, \mathrm{df}=2(\mathrm{P}=0.67) ; \mathrm{I}^{2}=0.0 \%$

Test for overall effect: $Z=1.57(P=0.12)$

Test for subgroup differences: Not applicable

Favours experimental Favours control 
Analysis I.4. Comparison I Outcomes of cognitive reframing interventions, Outcome 4 Coping/self efficacy.

Review: Cognitive reframing for carers of people with dementia

Comparison: I Outcomes of cognitive reframing interventions

Outcome: 4 Coping/self efficacy

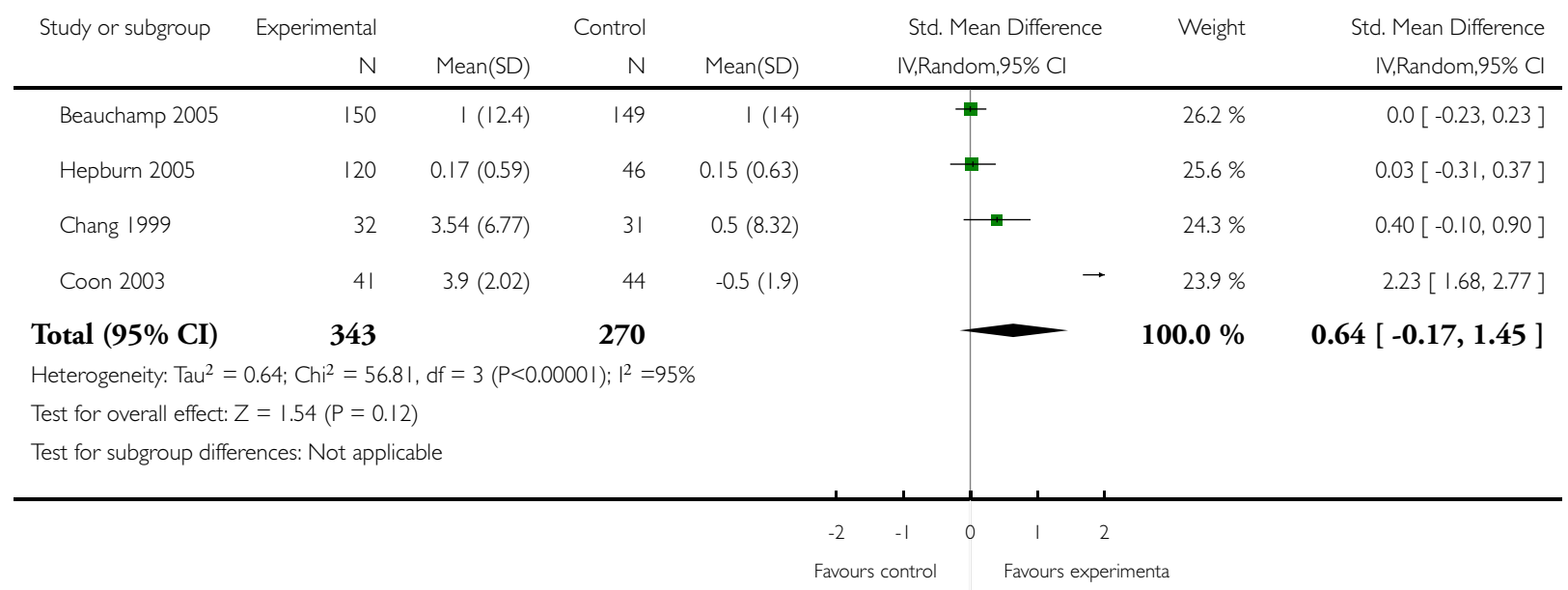


Analysis I.5. Comparison I Outcomes of cognitive reframing interventions, Outcome 5 stress/distress.

Review: Cognitive reframing for carers of people with dementia

Comparison: I Outcomes of cognitive reframing interventions

Outcome: 5 stress/distress

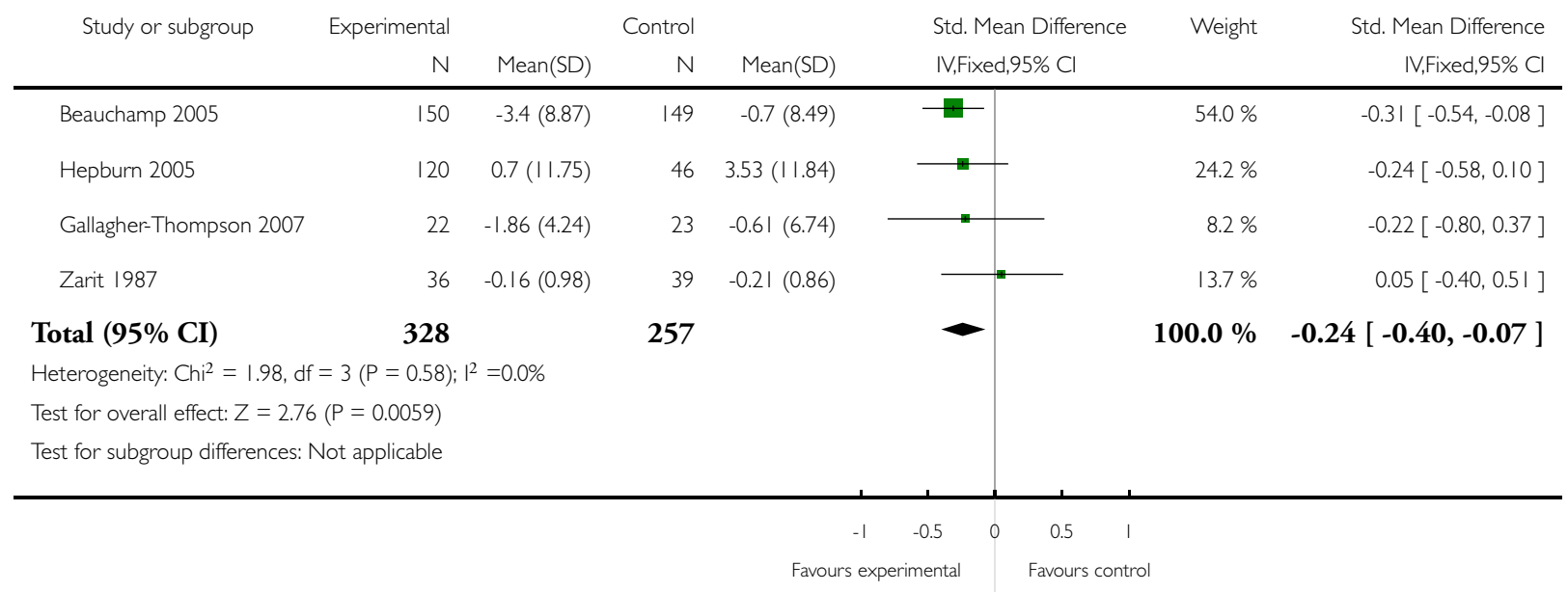

Analysis I.6. Comparison I Outcomes of cognitive reframing interventions, Outcome 6 RMBPC-reaction.

Review: Cognitive reframing for carers of people with dementia

Comparison: I Outcomes of cognitive reframing interventions

Outcome: 6 RMBPC-reaction

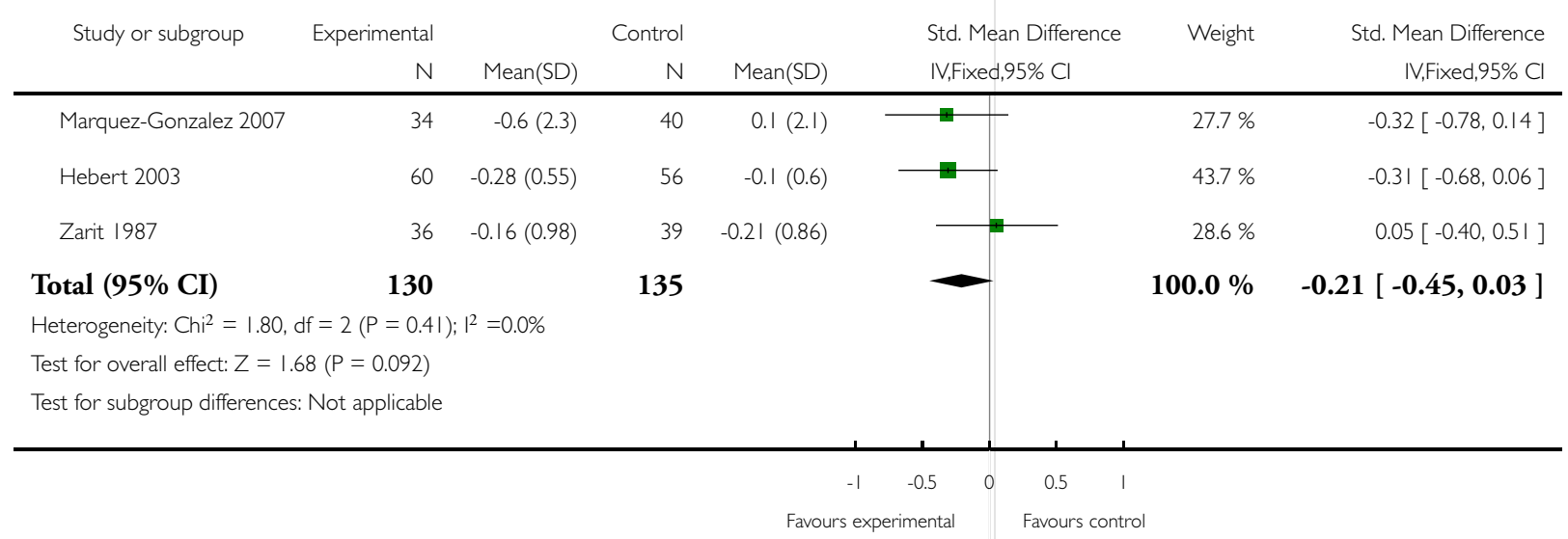


ADDITIONAL TABLES

Table 1. Assessment of study quality

\begin{tabular}{|c|c|c|c|c|c|c|c|}
\hline Study & $\begin{array}{l}\text { Sequence } \\
\text { generation }\end{array}$ & $\begin{array}{l}\text { Randomisa- } \\
\text { tion }\end{array}$ & $\begin{array}{l}\text { Base- } \\
\text { line compara- } \\
\text { bility }\end{array}$ & $\begin{array}{l}\text { Performance } \\
\text { bias: } \\
\text { blinding par- } \\
\text { ticipant and/ } \\
\text { or provider }\end{array}$ & $\begin{array}{l}\text { Detection } \\
\text { bias: Blind- } \\
\text { ing outcome } \\
\text { assessors }\end{array}$ & $\begin{array}{l}\text { Reporting at- } \\
\text { trition rate }\end{array}$ & $\begin{array}{l}\text { Use of inten- } \\
\text { tion to treat } \\
\text { analysis }\end{array}$ \\
\hline $\begin{array}{l}\text { 1. Akkerman } \\
2004\end{array}$ & $\mathrm{C}$ & A & A & B & A & A & B \\
\hline $\begin{array}{l}\text { 2. Beauchamp } \\
2005\end{array}$ & $\mathrm{C}$ & A & A & B & $\mathrm{C}$ & A & B \\
\hline $\begin{array}{l}3 . \quad \text { Chang } \\
1999\end{array}$ & $\mathrm{C}$ & A & A & B & $\mathrm{C}$ & A & B \\
\hline 4. Coon 2003 & $\mathrm{C}$ & A & A & B & A & A & B \\
\hline 5. Farran 2007 & B & A & A & B & A & B & B \\
\hline $\begin{array}{l}\text { 6.Gallagher- } \\
\text { Thompson } \\
2007\end{array}$ & $\mathrm{C}$ & A & A & B & $\mathrm{C}$ & A & B \\
\hline $\begin{array}{ll}7 . & \text { Hebert } \\
2003 & \end{array}$ & $\begin{array}{l}\text { A } \\
\text { Minimization } \\
\text { technique }\end{array}$ & A & A & B & A & A & A \\
\hline $\begin{array}{l}\text { 8. Hepburn } \\
2005\end{array}$ & $\begin{array}{l}\text { A } \\
\text { Block design } \\
\text { randomisa- } \\
\text { tion technique }\end{array}$ & A & A & B & $\mathrm{C}$ & A & B \\
\hline $\begin{array}{l}\text { 9. Marriott } \\
2000\end{array}$ & $\begin{array}{l}\text { A } \\
\text { Random } \\
\text { number tables }\end{array}$ & A & A & B & A & A & B \\
\hline $\begin{array}{l}\text { 10. Marquez- } \\
\text { Gonzalez } \\
2007\end{array}$ & A & A & A & B & B & A & A \\
\hline 11. Zarit 1987 & $\mathrm{C}$ & A & $\mathrm{C}$ & B & $\mathrm{C}$ & A & B \\
\hline
\end{tabular}


A P PENDICES

Appendix I. Sources searched and search strategies used

\begin{tabular}{|c|c|}
\hline Source & Search strategy \\
\hline MEDLINE (PubMed) & 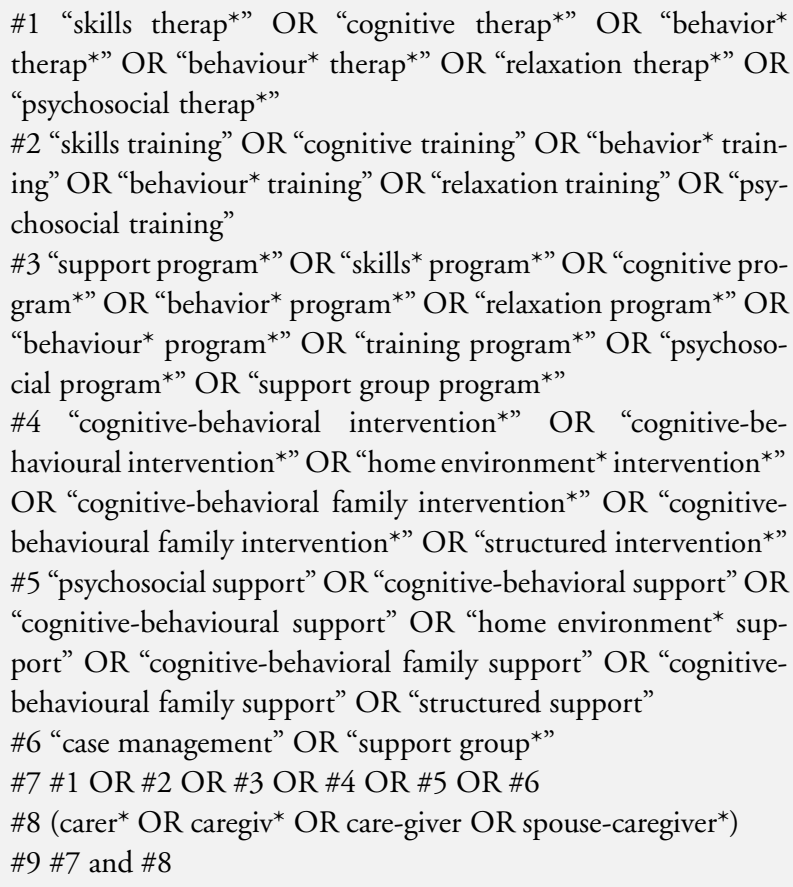 \\
\hline EMBASE (Ovid SP) & 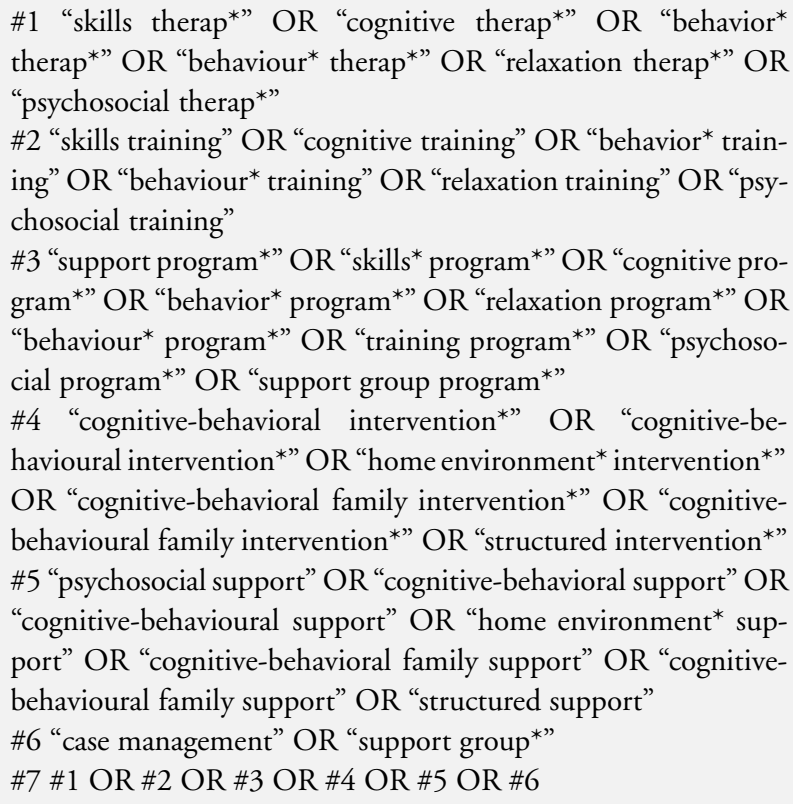 \\
\hline
\end{tabular}


PsycINFO (Ovid SP)

CINAHL (Ovid SP)
\#1 "skills therap*" OR "cognitive therap*" OR "behavior* therap*” OR "behaviour* therap*” OR "relaxation therap*” OR "psychosocial therap*"

\#2 "skills training" OR "cognitive training" OR "behavior* training” OR "behaviour* training” OR "relaxation training” OR "psychosocial training"

\#3 "support program*" OR "skills* program*” OR "cognitive program*” OR "behavior* program*” OR "relaxation program*” OR "behaviour* program*" OR "training program*" OR "psychosocial program*” OR "support group program*”

\#4 “cognitive-behavioral intervention*” OR "cognitive-behavioural intervention*" OR "home environment* intervention*" OR "cognitive-behavioral family intervention*" OR "cognitivebehavioural family intervention*" OR "structured intervention*" \#5 "psychosocial support" OR "cognitive-behavioral support" OR "cognitive-behavioural support" OR "home environment* support" OR "cognitive-behavioral family support" OR "cognitivebehavioural family support" OR "structured support"

\#6 "case management" OR "support group*"

\#7 \#1 OR \#2 OR \#3 OR \#4 OR \#5 OR \#6

\#8 (carer* OR caregiv* OR care-giver OR spouse-caregiver*)

\#9 \#7 and \#8

\#1 "skills therap*" OR "cognitive therap*" OR "behavior* therap*” OR "behaviour* therap*” OR "relaxation therap*” OR "psychosocial therap*"

\#2 "skills training" OR "cognitive training" OR "behavior* training” OR "behaviour* training" OR "relaxation training” OR "psychosocial training"

\#3 "support program*” OR "skills* program*” OR "cognitive program*” OR "behavior* program*” OR "relaxation program*” OR "behaviour* program*” OR "training program*” OR "psychosocial program*” OR "support group program*”

\#4 “cognitive-behavioral intervention*” OR "cognitive-behavioural intervention*" OR "home environment* intervention*" OR "cognitive-behavioral family intervention*" OR "cognitivebehavioural family intervention*” OR "structured intervention*” \#5 "psychosocial support” OR "cognitive-behavioral support” OR "cognitive-behavioural support" OR "home environment* support" OR "cognitive-behavioral family support" OR "cognitivebehavioural family support" OR "structured support" \#6 "case management" OR "support group*” \#7 \#1 OR \#2 OR \#3 OR \#4 OR \#5 OR \#6 \#8 (carer* OR caregiv* OR care-giver OR spouse-caregiver*) \#9 \#7 and \#8 
LILACS (Bireme)

CDCIG SR

CENTRAL (The Cochrane Library)
\#1 "skills therap*" OR "cognitive therap*" OR "behavior* therap*" OR "behaviour* therap*” OR "relaxation therap*” OR "psychosocial therap*"

\#2 "skills training" OR "cognitive training" OR "behavior* training" OR "behaviour* training" OR "relaxation training" OR "psychosocial training"

\#3 "support program*” OR "skills* program*" OR "cognitive program*” OR "behavior* program*" OR "relaxation program*” OR "behaviour* program*” OR "training program*" OR "psychosocial program*” OR "support group program*”

\#4 "cognitive-behavioral intervention*" OR "cognitive-behavioural intervention*" OR "home environment* intervention*" OR "cognitive-behavioral family intervention*" OR "cognitivebehavioural family intervention*" OR "structured intervention*" \#5 "psychosocial support" OR "cognitive-behavioral support" OR "cognitive-behavioural support" OR "home environment* support" OR "cognitive-behavioral family support" OR "cognitivebehavioural family support" OR "structured support"

\#6 "case management" OR "support group*”

\#7 \#1 OR \#2 OR \#3 OR \#4 OR \#5 OR \#6

\#8 (carer* OR caregiv* OR care-giver OR spouse-caregiver*)

\#9 \#7 and \#8

\#1 "skills therap*" OR "cognitive therap*" OR "behavior* therap*” OR "behaviour* therap*” OR "relaxation therap*” OR "psychosocial therap*"

\#2 "skills training" OR "cognitive training" OR "behavior* training" OR "behaviour* training" OR "relaxation training" OR "psychosocial training"

\#3 “support program*” OR "skills* program*” OR "cognitive program*” OR "behavior* program*” OR "relaxation program*” OR "behaviour* program*” OR "training program*” OR "psychosocial program*” OR "support group program*”

\#4 "cognitive-behavioral intervention" OR "cognitive-behavioural intervention*" OR "home environment* intervention*" OR "cognitive-behavioral family intervention*" OR "cognitivebehavioural family intervention*" OR "structured intervention*" \#5 "psychosocial support" OR "cognitive-behavioral support" OR "cognitive-behavioural support" OR "home environment* support" OR "cognitive-behavioral family support" OR "cognitivebehavioural family support" OR "structured support"

\#6 "case management" OR "support group*”

\#7 \#1 OR \#2 OR \#3 OR \#4 OR \#5 OR \#6

\#8 (carer* OR caregiv* OR care-giver OR spouse-caregiver*)

\#9 \#7 and \#8

\#1 "skills therap*" OR "cognitive therap*" OR "behavior* therap*” OR "behaviour* therap*” OR "relaxation therap*” OR "psychosocial therap*" 
\#2 "skills training" OR "cognitive training" OR "behavior* training" OR "behaviour* training" OR "relaxation training” OR "psychosocial training"

\#3 "support program*” OR "skills* program*” OR "cognitive program*” OR "behavior* program*” OR "relaxation program*” OR "behaviour* program*” OR "training program*” OR "psychosocial program*” OR "support group program*”

\#4 "cognitive-behavioral intervention*" OR "cognitive-behavioural intervention*" OR "home environment* intervention*" OR "cognitive-behavioral family intervention*" OR "cognitivebehavioural family intervention*" OR "structured intervention*" \#5 "psychosocial support" OR "cognitive-behavioral support" OR "cognitive-behavioural support" OR "home environment* support" OR "cognitive-behavioral family support" OR "cognitivebehavioural family support" OR "structured support" \#6 "case management" OR "support group*” \#7 \#1 OR \#2 OR \#3 OR \#4 OR \#5 OR \#6 $\# 8$ (carer* OR caregiv* OR care-giver OR spouse-caregiver*) $\# 9$ \#7 and \#8

ISTP Conference Proceedings http://portal.isiknowledge.com/ (Alzheimer* OR dement*) AND (carer* OR caregiver*) portal.cgi

Australian Digital Theses Program

(Alzheimer* OR dement*) AND (carer* OR caregiver*)

http://adt.caul.edu.au/

Canadian Theses and Dissertations

(Alzheimer* OR dement*) AND (carer* OR caregiver*)

http://www.collectionscanada.ca/thesescanada/index-e.html

WHO trials register

(Alzheimer* OR dement* ${ }^{*}$ AND (carer* OR caregiver*)

Current Controlled trials: Meta Register of Controlled trials (Alzheimer* OR dement*) AND (carer* OR caregiver*) (mRCT)

http://www.controlled-trials.com/

\section{ISRCTN Register}

(Alzheimer* OR dement*) AND (carer* OR caregiver*)

Nederlands Trial Register http://www.trialregister.nl/trialreg/ (Alzheimer* OR dement*) AND (carer* OR caregiver*) index.asp

ClinicalTrials.gov

(Alzheimer* OR dement*) AND (carer* OR caregiver*)

http://www.ClinicalTrials.gov

IPFMA Clinical Trials Register

www.ifpma.org/clinicaltrials.html

(Alzheimer* OR dement* ${ }^{*}$ AND (carer* OR caregiver*)

UMIN Japan Trial Register

(Alzheimer* OR dement* ${ }^{*}$ AND (carer* OR caregiver*)

http://www.umin.ac.jp/ctr/ 


\section{H I S T O R Y}

Protocol first published: Issue 2, 2005

Review first published: Issue 11, 2011

\section{CONTRIBUTIONS OFAUTHORS}

MV - all correspondence on protocol, assessment eligibility and methodological quality, drafting of protocol and review.

ID - assessment eligibility and methodological quality, meta-analyses, drafting of protocol and review.

JM - assessment eligibility and drafting of review.

MD - drafting of protocol.

Contact editor: Linda Clare

Consumer editor: Bernard Frijling

\section{DECLARATIONS OF INTEREST}

None known

\section{SOURCES OF SUPPORT}

\section{Internal sources}

- Centre for quality of care research / Alzheimer centre University Medical Centre Nijmegen, Netherlands.

- Bradford Dementia Group, Division of Dementia Studies, School of Health Studies, University of Bradford, BD5 OBB, West Yorkshire, UK.

\section{External sources}

- No sources of support supplied 


\section{DIFFERENCES BETWEEN PROTOCOLANDREVIEW}

The title has been changed, the original protocol was published under the title 'Cognitive and behavioural interventions for carers of people with dementia'. 